M. Köhler, K.P. Geigle, T. Blacha, P. Gerlinger, W. Meier, Experimental characterization and numerical simulation of a sooting lifted turbulent jet diffusion flame, Combustion and Flame 159 (2012) 2620-2635.

The original publication is available at www.elsevier.com

http://dx.doi.org/10.1016/j.combustflame.2012.01.015 


\title{
Experimental characterization and numerical simulation of a sooting lifted turbulent jet diffusion flame
}

\author{
M. Köhler*, K. P. Geigle, T. Blacha, P. Gerlinger, W. Meier \\ Deutsches Zentrum für Luft- und Raumfahrt (DLR), Institut für Verbrennungstechnik, Stuttgart, \\ Germany
}

\section{*Corresponding author:}

Dr. Markus Köhler

Institut für Verbrennungstechnik, Deutsches Zentrum

für Luft-und Raumfahrt (DLR), Pfaffenwaldring 38-40

70569 Stuttgart, Germany

Phone: $++49 / 711 / 6862-756$

Fax: ++49/711/6862-578

Email: M.Koehler@dlr.de

\section{Other authors:}

Dr. Klaus-Peter Geigle

Phone: $++49 / 711 / 6862-398$

Fax: $++49 / 711 / 6862-578$

Email: KlausPeter.Geigle@dlr.de

Dipl. Ing. Thomas Blacha

Phone: $++49 / 711 / 6862-364$

Fax: $++49 / 711 / 6862-578$

Email: thomas.blacha@dlr.de

Dr. Peter Gerlinger

Phone: ++49/711/6862-347

Fax: ++49/711/6862-578

Email: peter.gerlinger@dlr.de

Dr. Wolfgang Meier

Phone: ++49/711/6862-397

Fax: ++49/711/6862-578

Email: wolfgang.meier@dlr.de 


\section{Abstract}

A sooting $\mathrm{C}_{2} \mathrm{H}_{4} /$ air jet diffusion flame was investigated experimentally by laser measuring techniques and the results are compared to CFD calculations. The target flame $\left(\mathrm{C}_{2} \mathrm{H}_{4} 10.4 \mathrm{~g} / \mathrm{min}\right.$, bulk exit velocity $44 \mathrm{~m} / \mathrm{s}, \mathrm{RE}=10000$ ) exhibits well-defined boundary conditions and presents a good test case for model validation. Flow velocity, temperature and soot volume fraction in this flame has been measured previously. In this paper, further experimental results from Raman scattering and laser-induced fluorescence (LIF) measurements are presented to expand the validation data base. Raman scattering is used to measure the fuel/air mixing prior to combustion, while LIF of PAHs monitors the soot precursor region and successive planar OH-LIF serves to map the flame front position and its statistics.

Furthermore, a numerical simulation of this flame was performed based on the DLR in-house code THETA. Within the scope of the test case presented here, the code combines a relatively detailed description of the gas phase kinetics coupled with a detailed yet computation-efficient soot model, suitable for CFD applications. This model has been designed to predict soot for a variety of fuels and flames with good accuracy at relatively low computational costs. Universal model parameters are applied, which requires no tuning for the dependence of test case or fuel. The experimental and numerical results are compared and discussed with special emphasis on the pre-flame region of the jet and up to the downstream position where significant soot concentrations are present. Validation shows the general applicability of the CFD code with implemented soot model to rather complex systems like the target sooting turbulent jet flame. Identified discrepancies are analyzed and can be explained, while opening up the field for future optimization of parts of the CFD code.

\section{Keywords}

Soot, Jet Flame, Laser Diagnostics, Numerical Simulation, Nonpremixed, Turbulent Combustion, CFD, Validation Data, Ethylene 


\section{Nomenclature}

$\mathrm{K}_{\mathrm{e}}$ : dimensionless extinction coefficient

$M$ : molecular weight

$N_{\mathrm{r}}$ : number of reactions

$N_{\mathrm{sp}}$ : number of species

$P(\mathrm{~T})$ : probability density function for temperature

$P(\mathrm{Y})$ : probability density function for the species mass fraction vector $\mathrm{Y}=\left(\mathrm{Y}_{0}, \mathrm{Y}_{1}, \mathrm{Y}_{2}, \ldots\right)$

$S$ : chemical source term

$T$ : temperature

$c$ : concentration

$f_{\mathrm{v}}$ : soot volume fraction

$m$ : index of refraction

$t$ : time

n': stoichiometric coefficient on product side

n": stoichiometric coefficient on educt side

$k$ : Arrhenius reaction rate

Index

$\alpha, \beta$ : species index

r: reaction index 


\section{Introduction}

The emission of particulate matter from aircraft gas turbine engines, their potential impact on world climate and human health, and state-of-the-art methods for measuring particulate matter in engine exhaust are of international concern [1-2]. New combustion chamber geometries and injector concepts will be needed to fulfill increasingly stringent emission rules, making deeper understanding of the soot formation process more important than ever [3]. Soot emission is a known negative effect on environment and health and its presence indicates reduced combustion efficiency [4-6]. Within gas turbine combustion chambers, soot production is unwanted as it decreases the combustion efficiency and enhances thermal radiation, making soot a limiting factor in operability. Therefore, economic as well as environmental motivations are directly linked to the understanding of soot formation and growth.

To improve soot predictions for gas turbine engines and industrial combustors, computational fluid dynamic (CFD) approaches and kinetic soot model schemes need to be developed and adopted to relevant conditions. These must accurately treat turbulent mixing, combustion and particularly the complex chemistry of soot formation [7]. Clearly, one of the most demanding problems is the complexity of the formation process in flames, particularly in turbulent flames, as it is a multiparameter dependent phenomenon $[6,8]$.

Studies so far [9-10] emphasize the proceeding maturation of chemical kinetic mechanisms, but soot formation, growth and decomposition mechanisms are far from being well understood [9, 11-12]. Currently available detailed gas phase and soot mechanisms can contain the chemical kinetics of hundreds of intermediate species and thousands of reactions [13-14] and are still not complete. The major drawback of those large mechanisms is their requirement of extremely long computational times in CDF codes.

A recent overview of the evolution of soot models is given in [15]. Modern soot models cover a range from simple phenomenological models to sectional approaches, which is one of the most detailed soot modelling approaches available today. Unfortunately, phenomenological soot models at low computational cost often lack in general applicability and accuracy [16-18]. Modern numerical approaches with detailed gas phase chemistry, however, struggle with computational costs for technical applications, and are generally limited to rather simple test cases like laminar flames [8-9, 19-20]. Direct numerical solutions (DNS) are ideally suited for resolving turbulence effects and predicting even complex systems with high accuracy, but cannot be used for technical application due to high 
computational costs. Lignell et al. were able to perform DNS calculations for turbulent sooting flames, but with a very simple soot model [6]. This model features mainly the decomposition of ethylene $\left(\mathrm{C}_{2} \mathrm{H}_{4}\right)$ without taking the important PAHs into account. In this semi-empiric approach, soot is formed from acetylene, which is commonly regarded as the key species in soot formation and growth. However, the widely accepted HACA-mechanism for PAH and soot growth based on Frenklach and Wang [21] has not been implemented. Especially the reversibility of formation reactions from soot precursors is not covered.

Just recently, Bisetti et al. published a DNS calculation with a more detailed, modern soot model including PAHs [22]. Soot structures and turbulence are accurately resolved for a small flame at low Reynolds number. Due to the computational effort, however, no real flame could be calculated. The study is limited to a theoretical test case and a small region of the flame of $30 \times 20 \times 10 \mathrm{~mm}$. Although DNS approaches are advanced enough to handle complex sooting systems, the application to real gas turbine configurations is still out of question due to the lack in viability.

Recently, we presented a new sectional soot model [15] designed for technical applications with a reduced chemical kinetic gas phase mechanism by Slavinskaya et al. [10, 23]. Key features include soot size distributions at any point of the flame by capturing polycyclic aromatic hydrocarbon molecules (PAH) and soot at relatively low computational effort. Validation of the model was performed in a vast systematic study against various laminar test case flames covering a variety of fuels under different conditions. Note that the purpose of this approach was not higher accuracy than very detailed soot models, but the significant reduction of the computational cost allowing calculation of more complex test cases. Universal model parameters are applied, which require no tuning in dependence of the test case or fuel. Comparisons show a good prediction of soot volume fractions for several laminar flames covering a variety of different fuels (ethylene, propylene, kerosene surrogate, toluene) and combustion conditions (equivalence ratio, pressure). The wide range of applicability of this sectional soot model has been successfully demonstrated for simple test cases, e.g. zero-dimensional test cases, premixed onedimensional flames, non-premixed axisymmetric flames and partially premixed axisymmetric flames. Obviously, the next step is the investigation of more complex combustion systems building the bridge towards technical applications.

In our recent overview of turbulent sooting jet flames suitable for model validation purposes, the lack of a well-defined turbulent sooting flame is striking [24] and is equally emphasized in [6]. As implied before, to evaluate the quality of different available numerical approaches, experimental data for 
validation purposes is strongly needed, focusing on flames closer to technically relevant combustion processes. Modelers already have access to an exhaustive data base for laminar flames covering different fuels, vast parameter fields as well as exact defined systems. Suitable turbulent systems with sufficient soot and a comprehensive data base, however, are very rare in literature.

Motivated by this lack, we recently presented experimental data from a sooting turbulent jet flame based on modelers’ needs, filling the gap for sooting turbulent combustion test cases [24]. Simplicity, easy reproducibility and well defined boundary conditions were main aspects in finding a suitable flame from both the diagnostic and the numeric point of view. A lifted flame was chosen as the lift-off height is a sensitive criterion for model validation and, additionally, heat-up of the nozzle by the flame can be neglected. The flame has previously been investigated using particle image velocimetry (PIV), coherent anti-Stokes Raman scattering (CARS) and laser-induced incandescence (LII) building a vast data base for validation purposes. The description of the sooting jet flame and corresponding data sets of flow velocities, temperature and soot concentrations have been summarized in [24].

The present paper features two objectives. The first is the continuation of our work on the sooting jet flame to expand the validation data set and gain detailed insight in the soot formation processes for this turbulent flame. Planar laser-induced fluorescence (PLIF) of $\mathrm{OH}$ was applied to map the flame front position and statistics, while successive PLIF of PAHs qualitatively monitored the soot precursor region. Furthermore, special care has been taken to characterize the pre-flame region up to the initial soot formation zone of the jet flame with the Raman technique [25-29]. Laser Raman scattering was used to determine the mixing of fuel and air prior to combustion in the region close to the nozzle.

The second objective deals with the application of the THETA code with implemented soot model to the target flame. Due to the relatively low computational cost, the assumed-PDF approach could represent an attractive alternative to more detailed and costly models such as transported-PDF or DNS methods. Therefore, the next step in validating the soot model is the performance investigation on more complex systems. Making use of the comprehensive data base from this turbulent sooting jet flame, the THETA code with implemented soot model is applied and validated. Experimental results for temperature, flow field characteristics and soot properties are compared to computational values. The focus of this joint experimental and computational approach is the pre-flame region of the jet up to the downstream regions of initial soot formation followed by significant soot concentration. As soot and its precursor chemistry depend strongly and non-linearly on instantaneous temperatures, special attention is devoted on the comparison of the temperature distributions. Such detailed experimental characterization 
of the soot formation region allows identification of sensitive regimes in the soot model. This provides conclusions why certain computed quantities (e.g. mean temperatures on the flame axis or lift-off height) agree excellently, while others (e.g. soot concentrations) show only reasonable qualitative agreement.

Finally, we conclude with the discussion on present achievements and current limitations of our THETA code with soot model leading to new insights in soot formation in turbulent combustion processes, and opening perspectives for further optimization steps.

\section{Experimental}

\subsection{Burner configuration}

The lifted sooting turbulent jet flame has been described recently [24, 30]. Ethylene is issued from a straight tube with $2 \mathrm{~mm}$ inner diameter into a concentric, low-velocity co-flow. The co-annular dry air flows (320 g/min) through a contoured nozzle which converges from an inner diameter of $280 \mathrm{~mm}$ to $140 \mathrm{~mm}$ over a vertical distance of $310 \mathrm{~mm}$ and provides a homogeneous co-flow as oxidizer. To further shield the flame from air currents in the laboratory, the burner was mounted inside an optically accessible housing. Ethylene (99.95\% purity) was metered into the central tube at a rate of $10.4 \mathrm{~g} / \mathrm{min}$ via an electromechanical flow control unit (Bronkhorst F1C0-FAC-33-Z). This corresponds to a bulk flow-velocity of $44 \mathrm{~m} / \mathrm{s}$ at the jet-exit, and jet-exit Reynolds number of 10000 . The resulting flame is lifted and has a visible flame length of $400-500 \mathrm{~mm}$. The level of fluctuation is estimated to be on the order of +/-2 mm from the mean value, centring at $24 \mathrm{~mm}$ above the nozzle (determined by OH-PLIF). The burner was placed in the range of 110-150 cm under the laboratory exhaust hood. To change the measurement position, sub-mm precise movement of the jet burner was performed by a custom made translation stage.

\subsection{Planar laser-induced fluorescence measurements on $\mathrm{OH}$ and PAH}

The optical setup used for laser-induced fluorescence experiments is shown in Fig. 1a. The PLIF system consists of a frequency-doubled flash-lamp pumped Nd:YAG laser (Spectra Physics PIV-400-10) pumping a tuneable dye laser (Sirah PRSC-G-24-EG) with frequency-doubling unit to allow for UV excitation at $10 \mathrm{~Hz}$. The pulse energies at the measuring location were approximately $2.1 \mathrm{~mJ}$ with a band width of about $0.4 \mathrm{~cm}^{-1}$ and a pulse duration of $7 \mathrm{~ns}$. Excitation of $\mathrm{OH}$ on the $\mathrm{Q}_{1}(8)$ line of the $A^{2} \Sigma$ - $X^{2} \Pi(1,0)$ transition was performed at $\lambda=283.58 \mathrm{~nm}$. Wavelength tuning of the dye laser to the peak 
of the isolated $\mathrm{Q}_{1}(8)$ line was checked daily by a wavelength scan in a reference flame. Simulations by LIFBASE Version 2.0.6 [31] were used for interpretations and line selection, showing an approximately 9\% variation of the population of the laser-coupled ground state of the selected line in the temperature range between $1400 \mathrm{~K}$ and $2200 \mathrm{~K}$. For the PAH measurement, LIF images were obtained by de-tuning the laser off the $\mathrm{OH}$ transition to $283.54 \mathrm{~nm}$. More details on PAH spectroscopic properties will be discussed in the results section.

The laser beam was formed into a vertical sheet of $\approx 45 \mathrm{~mm}$ height and directed into the flame using two fused silica lenses ( $f=-25 \mathrm{~mm}, f=500 \mathrm{~mm}$ ) in a cylindrical telescope configuration and focused to a waist thickness of $0.4 \mathrm{~mm}$ using a third cylindrical lens $(f=550 \mathrm{~mm})$. The excited fluorescence signal was collected at $90^{\circ}$ by an achromatic UV lens ( $f=45 \mathrm{~mm}, \mathrm{f} / 1.8$, Cerco, AR coated) and detected by an intensified CCD camera (LaVision Flamestar II, 384x286 pixels). Scattering at $283 \mathrm{~nm}$ was blocked using a high-transmission (>80\% at $310 \mathrm{~nm}$, bandwidth $20 \mathrm{~nm}$ ) bandpass interference filter (Custom fabrication - Laser Components GmbH) and a color glass filter (1 mm thick WG295 Schott glass). The excitation wavelength of $283 \mathrm{~nm}$ provides insufficient photon energy for excitation of benzenoid species while the detection filter bandpass (305 - $325 \mathrm{~nm}$ ) excludes PAH having larger aromatic systems than anthracene or phenanthrene. The temporal detection gate of the image intensifier was set to 50 ns to reduce background luminosity.

LIF images were corrected for chip sensitivity, background luminosity and laser sheet inhomogenities. Background correction for the OH-PLIF images was performed by averaged images with a detuned laser to remove LIF generated by other species, whereas PAH-PLIF images were corrected for flame luminosity by blocking the laser. A beam profile correction has been implemented to correct all images on a single shot basis. For this purpose, part of the laser sheet was deflected by a beam splitter into a quartz cell filled with fluorescent dye solution (Coumarin 120 in methanol) and simultaneously imaged with a high-reflectivity UV-mirror on the camera described above. Therefore, every raw image contains the LIF information as well as the corresponding beam profile. The recorded dye cell profile was used for correcting laser sheet inhomogeneities on a single shot basis for both $\mathrm{OH}$ and PAH measurements. Spatial calibration of the images was accomplished using a dual-plane, three dimensional imaging target (LaVision Type 7); spatial resolution was measured to be $0.0882 \mathrm{~mm}$ per pixel. Image mapping, correction and calibration were performed with commercial software DaVis 7.2 (LaVision). 


\subsection{Laser Raman scattering measurements}

Laser Raman spectroscopy was applied to measure the fuel/air mixing ratios prior to combustion in the region close to the nozzle. The experimental setup is shown in Fig. 1b and has been described in detail previously [32]. The $489 \mathrm{~nm}$ output of a flashlamp-pumped dye laser (Candela LFDL 20) operated with Coumarin 102 at a repetition rate of $5 \mathrm{~Hz}$ was focused into the jet flame $(f=350 \mathrm{~mm})$ after beam expansion by a telescope. After passing through the flame, the laser beam was retro-reflected by a spherical mirror $(f=350 \mathrm{~mm})$ into the flame and back into the laser resonator. This quasiintracavity configuration yielded an effective pulse energy of $1.5 \mathrm{~J}$ with a pulse duration of $\approx 3 \mu$ s. The Raman scattering emitted from the measuring volume $(0.6 \mathrm{~mm}$ in all dimensions) was collected by an achromatic lens $(f=160 \mathrm{~mm})$ and relayed to the entrance slit of a spectrograph (SPEX 1802, $f=1000$ $\mathrm{mm}$, dispersion $\approx 0.5 \mathrm{~nm} / \mathrm{mm}$ ). The dispersed and spatially separated signals from the different major species were detected by individual photomultiplier tubes (Hamamatsu R928, R3896) in the focal plane of the spectrograph and sampled using boxcar integrators (Stanford Research Systems SR250). The species number densities were calculated from these signals by comparison with the signals from pure air and ethylene; the RMS fluctuations for each Raman measurement are included as error bars. Because the system was not calibrated for ethylene/air flames and strong signal interferences from soot precursors make Raman measurements in sooting flames very inaccurate, measurements were only performed in regions without reaction products. Since the focus was on the determination of the fuel/air mixing prior to combustion, regions with combustion products were masked from further analysis of the mixing ratios. However, the borderline of the masked area serves as an indicator for the onset of combustion.

\subsection{Measurement techniques for soot concentrations, flow velocities and flame temperatures}

Compared to the previous publication [24], there are no new results from measurements of soot concentration, flow velocity and flame temperature. However, in order to compare experimental and simulated results, some figures contain these quantities and additional statistical analysis that has been performed. A detailed description of the corresponding measurement technique was given in [24], thus here only a very brief summary is presented.

Soot concentrations were measured by laser-induced incandescence (LII) using a Nd:YAG laser (Spectra Physics, GCR3-290) with 7 ns pulse duration at $1064 \mathrm{~nm}$, and $10 \mathrm{~Hz}$ pulse repetition rate. The beam was formed to a sheet of $40 \mathrm{~mm}$ height and $0.2 \mathrm{~mm}$ thickness and irradiated through the centre of 
the flame. The LII signal was detected by an intensified interline frame transfer CCD camera (Dicam Pro, PCO, 1280x1024 pixels), equipped with an interference filter (LOT 450 FS40-50) centred at $\lambda=$ $450 \pm 10 \mathrm{~nm}$ and a Nikon lens $(f=105 \mathrm{~mm}, \mathrm{~F} 2.5)$. Images were corrected for chip sensitivity, background luminosity and gain settings. Calibration of the soot images was performed by extinction measurements using a fiber-coupled laser system with a solid-state laser emitting at $\lambda=1064 \mathrm{~nm}$ (LCLLCS-DTL-322-1000, Laser2000). Based on earlier investigations [33], the calculations in [24] were carried out using the index of refraction, $m$ of 1.60-0.59i. This arbitrarily chosen value out of the range found in literature is consistent with our earlier publication [24] on the presented target flame, resulting in a dimensionless extinction coefficient $K_{e}$ of 5.01 [34] for both the extinction (1064 nm) and LII detection wavelength $(450 \mathrm{~nm})$. The total uncertainty for the soot volume fraction was estimated to be $20 \%$.

Flow velocities were measured by particle image velocimetry (PIV) using a single cavity frequencydoubled Nd:YAG laser (Spitfire 600, InnoLas) frequency-doubled to $532 \mathrm{~nm}$ producing a pair of laser pulses with an interpulse delay of $40 \mu \mathrm{s}$. The laser was formed into a thin, collimated sheet (60x0.5 mm) passing through the flame axis of symmetry. The PIV signal was detected by an interline frame transfer CCD (Imager Intense, LaVision GmbH, 1376x1040 pixels); the camera was equipped with a $1 \mathrm{~nm}$ bandpass filter (532 FS02, Andover Corporation) transmitting the scattered radiation centred at $\lambda=532 \mathrm{~nm}$ and a Nikon camera lens $(f=50 \mathrm{~mm}$, F8.0) fitted with a mechanical shutter (LaVision GmbH, Model 1108323) with a close time of approximately $7 \mathrm{~ms}$. Both fuel and co-flow streams were seeded with titanium dioxide $\left(\mathrm{TiO}_{2}\right)$ particles (nominal diameter of $0.5 \mu \mathrm{m}$ ) via a particle seeder (Particle Blaster 100, LaVision GmbH). The PIV vectors were obtained by cross-correlating the raw images using the DaVis 7 software (LaVision GmbH). The DaVis multi-pass algorithm with interrogation windows decreasing in size from 128x128 to 32x32 pixels and 50 \% overlap was used to process the PIV images.

Temperatures were measured by shifted-vibrational coherent anti-Stokes Raman spectroscopy (SVCARS) using the $532 \mathrm{~nm}$ emission of a Nd:YAG laser (GCR230, Spectra Physics, $10 \mathrm{~Hz}$ ) to pump a customized dye laser system (Precision Scan, SIRAH Laser- und Plasmatechnik GmbH), composed of one narrowband unit ( $\lambda=582 \mathrm{~nm}$, pyrromethene, $0.16 \mathrm{~g} / \mathrm{l}$ in ethanol, $42 \mathrm{~mJ} / \mathrm{pulse}$ ) and one broadband unit ( $\lambda=685 \mathrm{~nm}$, pyridin-1, $0.25 \mathrm{~g} / \mathrm{l}$ in ethanol, $31 \mathrm{~mJ} /$ pulse). The pulse energies used depended on the $\mathrm{N}_{2}$ density at the measurement location and were in the range of 4-13 mJ for the broadband beam and 9$27 \mathrm{~mJ}$ for the narrowband beam. After the attenuator, the narrowband beam was split in two and the 
three laser beams were focussed in a folded BOXCARS geometry by a spherical lens ( $f=350 \mathrm{~mm}$ ). After recollimation the CARS signal was separated from the laser beams by an aperture and two dichroic mirrors and subsequently focussed into a fiber (UV400, Avantes). The CARS signal was dispersed on a double-grating spectrograph (Model 1403, Spex) and recorded by an iCCD camera (Flamestar 2F, LaVision). From a measurement without a flame, the spatial resolution was found to be $L_{95 \%}=2.2 \mathrm{~mm}$ with a diameter of the probe volume of approximately $300 \mu \mathrm{m}$.

\section{Simulation}

\subsection{Numerical Model}

The simulation of the turbulent jet flame has been performed with the in-house DLR CFD code THETA - an incompressible flow solver for finite-volume grids optimized for combustion problems and in use for over 10 years [35-36]. It features a pressure correction method (SIMPLE or Projection), dual grid technique, preconditioned for faster convergence, and different efficient solver algorithms including multigrid. Parallelization has been realized via domain decomposition. Transport equations are solved for the flow field and all species, expect the last one, which is calculated using the law of Dalton. Turbulence is accounted for using the cost efficient two equation k- $\varepsilon$-model by Jones et al. [37] in order to limit the computational effort. The impact of turbulence on chemical reaction rates is represented by a multivariate assumed PDF approach according to Gerlinger [38-41] and Di Domenico [42].

The soot model consists of three sub models describing molecular gas phase species, PAHs, and soot. For the simulation of the turbulent ethylene flame, the chemical kinetic mechanism of the gas phase consists of 43 species and 304 elementary reactions [15]. Aromatic molecules are represented by three logarithmically spaced mass sections ranging from 100-800 amu; the first bin $\mathrm{PAH}_{0}$ ranges from 100200, $\mathrm{PAH}_{1}$ from 200-400 amu and $\mathrm{PAH}_{2}$ from 400-800 amu. Soot has been incorporated by a sectional approach, in order to be able to determine soot particle size distributions. 25 soot sections have been used covering a range from $800 \mathrm{amu}$ up to $2.710^{10} \mathrm{amu}$ or $\approx 300 \mathrm{~nm}$. The overall reaction mechanism consists of 71 species and 803 reactions. Detailed information on the complete soot model is provided by Blacha et al. [15]. Due to the relatively complex gas phase chemistry, PAHs and soot model, the computational effort is high. Thus an efficient two-equation $\mathrm{k}-\varepsilon$-model turbulence model is used to close the set of governing equations. 
Detailed chemistry, involving a great number of species with hundreds of reactions, usually comes along with a high degree of stiffness. In order to efficiently solve the governing equations, the chemical source term is treated implicitly. The required Jacobian for the system has been calculated analytically because this procedure is not only more accurate than the numerical alternative, but also faster.

Since the chemical source term is highly non-linear in species concentration and temperature space, the required averaged chemical source term is not directly be calculated from averaged temperatures and species concentrations. Assuming statistical independence between temperature and species fluctuations, the averaging of the chemical source term can be described as:

$$
S_{\alpha}=M_{\alpha} \frac{d c_{\alpha}}{d t}=-M_{\alpha} \sum_{r=1}^{2 N_{r}}\left[v_{\alpha, r}\left(k_{r} \prod_{\beta=1}^{N_{s \beta}} c_{\beta}^{v_{\beta}^{\prime}, r}\right)\right]
$$

Equation (1) can be split into a species and a temperature dependent part:

$$
\overline{S_{\alpha}}=-M_{\alpha} \sum_{r=1}^{2 N_{r}}\left[v_{\alpha, r}^{\prime} \overline{\frac{k_{r}}{T^{\sum v_{\beta, r}^{\prime}}}} \bar{T}^{\sum v_{\beta, r}^{\prime}} \cdot \overline{\prod_{\beta=1}^{N_{p}+1} c_{\beta}(\bar{T})^{v_{\beta, r}^{\prime}}}\right]
$$

For averaging in temperature space, a clipped Gaussian temperature-PDF is assumed, while the species dependent part is averaged using Girimajis multivariate $\beta$-PDF [43-44]. It follows:

$$
\overline{\frac{k_{r}}{T^{\sum v_{p, r}^{\prime}}}} \cdot \bar{T}^{\sum v_{b, r}^{\prime}}=\bar{T}^{\sum v_{p, r}^{\prime}} \int\left(\frac{k_{r}}{\hat{T}^{\sum v_{b, r}^{\prime}}}\right) P(\hat{T}) d \hat{T}
$$

and

$$
\prod_{\beta=1}^{N_{\rho_{p}+1}+1} c_{\beta}^{v^{\prime}, r, r}=\int\left(\prod_{\beta=1}^{N_{p}+1} c_{\beta}^{v^{\prime}{ }^{\prime}, r}\right) P(\hat{\boldsymbol{Y}}) d \hat{\boldsymbol{Y}}
$$

For reasons of computational efficiency, the averaging in temperature space is done in preprocessing. The calculated values are stored in lookup tables, which are then used during run time. For the averaging in species mass fraction space, an integration of the multivariate $\beta$-PDF is necessary. Here, an analytical solution is applied during run time.

The averaging in temperature space is also applied for the OTA heat radiation model in direct analogy to the averaging of the chemical source term. The equations for the heat sink have been derived from the work of Mauß [45] and can be found in detail in Blacha et al. [46]. 


\subsection{Boundary conditions and numerical considerations}

The input parameters for the simulation are chosen according to the experimental conditions where ethylene was injected by a $2 \mathrm{~mm}$ inner and $6 \mathrm{~mm}$ outer diameter steel pipe at a velocity of $43.56 \mathrm{~m} / \mathrm{s}$. The fuel was issuing into a surrounding co-flow air with an axial velocity of $0.29 \mathrm{~m} / \mathrm{s}$ in order to have well defined boundary conditions for the simulation. The temperatures of fuel (297 K) and air (297 K) were measured by thermocouples and the fuel pipe heat-up was determined to be about $10 \mathrm{~K}$. For the

laminar Prandtl and Schmidt numbers, needed for temperature and species diffusion, values of 0.7 has been used. The turbulent Prandtl and Schmidt numbers have been set to 0.8 and 0.7 , respectively, in concordance with the findings in similar round jet test cases [47].

Stationary calculations are performed on an axisymmetric five degree slice discretized with a grid containing hexahedral cells defined by 52000 nodes. In the reaction zone and close to the fuel injection the grid resolution is finer than in regions far away from the flame front. The maximum grid contraction ratio was 1.1 in regions upstream of the fuel injection and 1.05 elsewhere. The computational domain extended $70 \mathrm{~mm}$ in radial direction, $42 \mathrm{~mm}$ upstream, and $410 \mathrm{~mm}$ downstream of the fuel injector.

\section{Results and discussion}

\subsection{Experimental flame characterisation}

The following section describes new experimental data from the jet flame augmenting the previously published validation data set [24]. For reasons of clarity Fig. 2 includes results from the previously reported data set, especially for local correlation of the soot field to the newly acquired data on $\mathrm{OH}$ and PAHs.

\subsubsection{Soot, $\mathrm{OH}$ and PAH distributions}

Figure 2 shows two-dimensional soot, $\mathrm{OH}$ and $\mathrm{PAH}$ distributions. Each section consists of a random compilation of single-shot images, the time-averaged images and corresponding RMS values. All image series were recorded at 13 different heights above the burner and stitched together to produce mappings of the complete flame area.

A random collage of instantaneous soot concentration mappings is shown in Fig. 2a. Instantaneous soot concentrations exceed $5 \mathrm{ppm}$ in the upper region of the flame. This collage gives insight in the typical shape and distribution of the soot volume fraction $f_{\mathrm{V}}$ for this flame. Averaging 1000 single-shot images provides smooth 2D-time-averaged soot volume fraction images, (Fig. 2b), while corresponding 
RMS values are shown in Fig. 2c. The average $f_{\mathrm{v}}$ is determined to be $0.54 \mathrm{ppm}$. A more detailed discussion and analysis of the measured soot data can be found in [24].

The results from the OH-PLIF measurements are shown in Figs. 2d-f. The OH radical is often considered a useful intermediate species in combustion to visualize the flame front, since $\mathrm{OH}$ is formed in the reaction zone and rapidly converted at lower temperature. Therefore, the location and shape of the reaction zones and high temperature regions are reflected by the $\mathrm{OH}$ fluorescence signal [48].

The random collection of single-shot images in Fig. 2d shows initial formation of $\mathrm{OH}$ in high concentration after $24 \mathrm{~mm}$ above the jet nozzle evolving into a thin-walled tubular structure. The location of the radial maximum is relatively stable in the initial flame part. Thickness and fluctuations increase downstream in the flame. The $\mathrm{OH}$ signature broadens in the upper part of the flame beyond $\mathrm{h}=$ $250 \mathrm{~mm}$ and becomes highly wrinkled, or convoluted, and spatially distributed when moving downstream from the burner. The overall observation is well-known for lifted jet flames and is in good agreement with other reports on lifted jet flames [49]. Comparing the instantaneous $\mathrm{OH}$ distributions to the soot structures, major differences are noted. The $\mathrm{OH}$ sheet is continuous without breaches and rather smooth in the lower part of the flame. In contrast, the soot structures are broader and highly wrinkled. The $\mathrm{OH}$ signature is mostly single layered while the soot filaments are wrinkled and start forming linked structures onwards. In the lower part of the flame distinct regions can be identified where the soot field is mostly inside the $\mathrm{OH}$ zone. The soot distributions are characterized by high spatial dynamics in the whole flame while $\mathrm{OH}$ remains very localized. As expected, the turbulent flow in the lower part of the flame is laminarized by the heat release due to the viscosity increase. Therefore, the hot $\mathrm{OH}$ zones appear very smooth. Inside the $\mathrm{OH}$ layer, however, the mixtures are rich and the temperature is lower, thus soot is formed showing much more turbulent structures compared to the $\mathrm{OH}$ zone.

Figure 2e shows a collage of averaged $\mathrm{OH}$ concentrations for the full flame length with the corresponding RMS image in Fig. 2f. The results from the LII measurements are averaged over 1000 instantaneous images. For the lower third of the flame, spatial fluctuations of the $\mathrm{OH}$ distribution are marginal and the signature virtually has a hollow closed cylindrical shape with weak distortions in the single shots. The highly diffuse character in the single shot images further downstream is coincident with larger spatial fluctuations resulting in radially smooth distributions, spreading to the flame axis. The results from the successive PAH-PLIF measurements are shown in Figs. 2g-i. PAHs are discussed and acknowledged as important soot precursors. They contain fused aromatic rings forming one of the building blocks of soot. However, their chemical composition and structure is quite divers. Individual 
PAH identification in flames by using the LIF technique is known to be challenging because vibronic lines are significantly broadened and overlap under these conditions. The resulting unspecific broadband excitation and emission characteristics of PAH complicate the spectroscopic flame analysis. Hayashida et al. [50] report the extremely challenging selective excitation and detection of individual PAH in a flame, however, the measurement of the concentration distribution of individual PAH had not been achieved directly by LIF. It is known that the energy separation between the electronic excited state and electronic ground state decreases with increasing size of PAH [51]. Therefore, the fluorescence shifts toward longer wavelengths as the size of PAH increases, when details of their shape and side chains are neglected. Since individual selection of the PAH is not strictly achievable by laser excitation, the classification of PAH size might be performed using the fluorescence signal, because the fluorescence wavelengths roughly reflect the size of PAH [50]. Hayashida et al. performed an exhaustive literature research and analysis on the emitted PAH fluorescence signal, concluding in a correlation between the maximum emission wavelength and the carbon number. Based on this analysis and the excitation wavelength as well as the specifications of the filter used in front of the detection camera $(>80 \%$ at $310 \mathrm{~nm}$ ) the carbon number is to be in the range of 10-14 in our measurements. This estimation includes major soot precursor species like naphthalene $\mathrm{C}_{10} \mathrm{H}_{8}$, fluorene $\mathrm{C}_{13} \mathrm{H}_{10}$, anthracence $\mathrm{C}_{14} \mathrm{H}_{10}$ or phenanthrene $\mathrm{C}_{14} \mathrm{H}_{10}$ [50]. Although due to unavailable quenching coefficients a conclusion on concentrations of individual species cannot be drawn from the measurements, the carbon number range compares to the first PAH bin cluster (mass range 100-200 amu) used in the soot model and is thus suitable for validation.

Given the relative low fluence of the UV laser $\left(0.1 \mathrm{~mJ} / \mathrm{mm}^{2}\right)$ and the spectral detection band around $315 \mathrm{~nm}$ no significant LII contribution to the PAH images is expected. Moreover, no signatures typical for LII could be found in the clearly different OH PLIF images using the same detection scheme as our PAH PLIF.

The collage of random instantaneous two-dimensional images in Fig. 2g reveals the presence of PAHs mainly in the central flame zone. Compared to soot, PAH signatures are closer to the flame axis and exhibit a more homogeneous low-intensity offset. While PAH structures are quite smooth, almost continuous and stationary in the lower part of the flame, the upper flame region is dominated by more wrinkled and convoluted structures showing great resemblance to the soot structures, apart from the offset intensity. 
The ensemble-averaged distribution in Fig. 2i is obtained from 500 single-shot images. Due to weaker PAH-LIF emission, we employed a higher camera gain than for the $\mathrm{OH}$ measurements. In comparison to the average soot image, the PAH image reveals a similar, but narrower distribution. Axial peak values of PAH appear a bit earlier in the flame than the corresponding soot concentrations. The strongest fluctuations and large scale structures occur close to the end of the flame. Low in the flame, the PAH distribution is located inside the $\mathrm{OH}$ envelope. Looking at the initial part of the flame, PAHs formation is found earlier in the flame than soot formation, as expected. The annular structure observed in the soot distribution is also present, but converges soon thereafter. In comparison with the $\mathrm{H}_{2}$-piloted ethylene jet flame studied by Lee et al., the same characteristic features of the PAH and soot mappings are found throughout the flame [52]. Noticeable differences are the initial annular structure in the lifted flame here that were not observed for the attached flame by Lee et al.

\subsubsection{Raman scattering measurements}

Raman scattering has been applied to the region prior to combustion to gain information on fuel mixture fraction. Since mixing of the fuel and air is crucial for model validation, a fine grid of 115 measurement locations up to $\mathrm{h}=30 \mathrm{~mm}$ from the centreline to $\mathrm{r}=10 \mathrm{~mm}$ has been chosen for detailed mapping. Results from the Raman measurements performed in the combustion region are not displayed here due to the missing calibration for the combustion products.

Figure 3 shows the color plots obtained from the Raman scattering measurements; the signal for each location is averaged over 400 single shot events. Apart from minor asymmetries as visible in Fig. 3 that are discussed below, the general distributions show reasonable axial symmetry.

The fuel mole fraction is shown in Fig. 3a with the corresponding RMS values in Fig. 3b. In general fuel fraction follows the trends of a high velocity jet issuing into almost stagnant air. It decreases slowly along the axis as air and fuel get increasingly mixed. This correlates to initial radial gradients being steep and getting smoother with increasing distance from the jet nozzle. The area above $\mathrm{h}=22 \mathrm{~mm}$ in the flame front region has been masked from the analysis because combustion products were present at least in some shots. However, the masked area indicates the onset of combustion. Comparison with the $\mathrm{OH}$ (this paper) and $\mathrm{OH}^{*}[24]$ measurements confirms the onset of flame activity in that area.

\subsection{Global flame simulation}

In the following section, numerical results are compared to experimental measurements. The described soot model has already been used and validated for a variety of laminar test cases showing 
good predictive capabilities at moderate computational cost [15]. Here, the actual turbulent test case

provides an increased complexity. The goal is not to show higher accuracy compared to detailed soot models, but to test the predictive capability and feasibility for still more complex combustion systems (e.g. aero-engines or gas turbine combustion) without the need to modify the chemical mechanism. One of the challenging issues is the correct simulation of flame stabilization. In the investigated flame the lift-off height presents a sensitive criterion for the capability of the model.

A compilation of the two-dimensional images of temperature, velocity and soot is shown in Fig. 4. The simulation is always presented on the left side, the corresponding experimental images on the right side of each column (if available). In the following, each quantity will be analysed and discussed.

\subsubsection{Model validation: Temperatures}

Figure 4a shows the calculated two-dimensional mean temperature field. A 2D experimental temperature plot is not available because temperatures were measured point wise and only for a limited number of radial locations.

The simulated temperatures show a steep gradient at a height of around $25 \mathrm{~mm}$ where ignition takes place. This shows a very good agreement with the experimentally observed reported lift-off height of 26 mm [24] determined by $\mathrm{OH}$ chemiluminescence. The lift-off height also strongly depends on the turbulent diffusion process and on turbulence chemistry interactions, which have both been captured by simplified models. Note that the previous lift-off height has been determined experimentally as the maximum signal of deconvoluted $\mathrm{OH}$ chemiluminescence images [24]. When using the actual spatially resolved OH-LIF image, which provides more precise experimental data, a lower lift-off height is identified as the location of the vertical signal gradient. To determine the lift-off height and its fluctuations, we determined the half-intensity position relative to the typical plateau level of the lower flame front branch. Figure 5 shows a typical instantaneous $\mathrm{OH}$ image, followed by axial profiles for each branch. Flame islands were ignored. Statistically, the quantity deduced from the planar image should be well representative for the 3D flame front. Fig. 5c shows the statistics of the determined $\mathrm{OH}$ gradient and is therefore an indicator of the level of fluctuation for the lifted jet flame. Statistics over 500 images results in a Gaussian type distribution with a resulting lift-off height of $22.3+/-1.5 \mathrm{~mm}$. The simulated value of $25 \mathrm{~mm}$ is in good agreement with both experimentally determined values.

In Fig. 6a, the calculated mean temperature along the burner axis is compared to the experimental data. In addition to the mean values, the square root of the temperature variance (standard deviation) is shown as a grey band, being an indication for the range of the assumed Gaussian distribution. As far as 
the SV-CARS temperature measurements are concerned, $\mathrm{T}_{\text {mean }}$ represents the average temperature without any weighting; $\mathrm{T}_{\mathrm{mp}}$ denotes the temperature with the highest probability and the bars the interval including $90 \%$ of all measured values. Besides $\mathrm{T}_{\text {mean }}$ these two quantities are suited to characterize the temperature distribution and the fluctuations. A generally good agreement is observed between simulation and experiment along the centreline, especially for the first part of the flame up to $200 \mathrm{~mm}$. This observation holds for mean values as well as for the distribution width. Only far downstream in the highly intermittent region where fluctuations peak and very low temperatures occur, temperatures are slightly over predicted by the model. This is most probably due to the influence of heat radiation from soot species which is much likely under predicted by the CFD calculation in this region [15]. Systematic deviations are found in the part of the flame tip region. A careful analysis of the experimental results indicates that temperatures above $\mathrm{h}=350 \mathrm{~mm}$ were probably under predicted, resulting in a systematic lower mean temperature. As discussed in [24], the most probable temperature $\mathrm{T}_{\mathrm{mp}}$ is the one recommended for model validation purposes.

The deviation in temperature is due to the use of a rather simple heat radiation model (OTA). More detailed heat radiation models exist in the literature [53-55] but they also imply a higher computational cost. Liu et al compared OTA with SNBCK/DOM for a laminar diffusion ethylene/air flame showing little differences in the prediction of temperatures [56]. However, when applied to turbulent flames new mechanisms come into play, such as the impact of turbulent temperature fluctuations. A further reason for deviations in temperature can be associated to the general uncertainty of soot enthalpy values as demonstrated by Blacha et al.

For a Gaussian distribution $\mathrm{T}_{\text {mean }}$ and $\mathrm{T}_{\mathrm{mp}}$ are identical, but in contrast to the model assumption, the measured distributions are not strictly Gaussian. Figure 7 is a representative collection of experimental probability density functions for selected heights along the centre line with a Gaussian fit to the data points; deviations of $\mathrm{T}_{\mathrm{mp}}$ relative to $\mathrm{T}_{\text {mean }}$ are indicative of the fit quality. A Gaussian-like behaviour is observed for the central heights in the flame with deviations below and above. Therefore, the model assumption of a Gaussian temperature distribution is not fully valid in the regions where mean and most probable temperatures differ. This becomes even more eminent in the far downstream region as the difference increases significantly.

Figures 6b-d display the experimental and computational radial temperature profiles at $\mathrm{h}=63 \mathrm{~mm}$, $113 \mathrm{~mm}$ and $213 \mathrm{~mm}$. The highest CARS measurement position of $413 \mathrm{~mm}$ is omitted, since the highly dynamic flame tip is considered unsuited for validation purposes. As already evident from Fig. 6a, at the 
centreline of the radial plots, calculated averaged temperatures and temperature distributions are in very good agreement with the experimental results. Moving away from flame centre, the experimental temperatures rise faster than the predicted values. This trend is observed for all heights, i.e., the calculated temperature profiles are broader than the experimental ones. Because CARS measurements have not been performed in the outer region of the flame, a comparison between simulation and experiment is not possible for large radial positions. However, the additional Raman measurements are used to identify the radial location where the composition and temperature is always (i.e. $100 \%$ of laser shots) at room conditions; the corresponding $x$-bar displays the maximum assumed spatial error for this region. The relatively large error bar is due to a misalignment of the burner axis in the Raman measurement. These cold-temperature fix points are added to each radial profile in Fig. 6b-d as an indicator for the outer limit of the combustion zone to provide a more detailed data set. However, even with this uncertainty the transition between combustion and no combustion is significantly closer to the flame centre than predicted by the simulation, confirming the above statement about the deviations between the measured and simulated temperature profiles. Thus, the width of the flame is over predicted by the simulation. On the other hand, the temperatures and temperature distributions in the central flame region as well as the lift-off height agree quite well.

\subsubsection{Model validation: Velocities}

The two dimensional color plots of the calculated mean axial velocities are shown in Fig. 4b. The measured velocity component is obtained from averaging two hundred single shot PIV measurements, recorded at eight different heights above the burner and concatenated to generate one single image. Experimental and calculated results are quite similar in shape and magnitude. In Fig. 8a experimental and simulated mean axial velocity profiles on the centreline are displayed and show good agreement, especially in the far downstream region. Close to the burner, the model slightly under predicts the axial velocities near the flame axis. It should be noted that the application of PIV to a heavily sooting flame is challenging and very rarely reported in literature. Sooting flames have a strong luminescent background reducing the signal-to-noise ratio of the PIV particles significantly compared to non-sooting flames. Figures $8 \mathrm{~b}$ displays the respective comparison of the radial profiles of the mean axial velocity at four heights. It shows only reasonable agreement for the lower heights where the simulated peak values are

smaller. Further downstream the discrepancies become smaller. Compared to the experiment, the simulated velocities are higher at the periphery of the flame, i.e. the jet width is over predicted by the 
simulation. This is consistent with the conclusion of the temperature section above. Very good agreement is observed for the highest profile at $\mathrm{h}=363 \mathrm{~mm}$.

The quality of the calculated flow field significantly influences, the accuracy of the overall model performance. Deviations resulting from uncertainties in the turbulence modelling have an impact on the transport of key species. The standard k- $\varepsilon$-model by Jones et al. [37] predicts flow fields of planar jet configurations very well, but it is well known to be responsible for significant errors for axisymmetric jets; this phenomenon is described in literature as the "round-jet"-anomaly. The anomaly is the result of various assumptions in the derivation of the Reynolds-averaged Navier-Stokes equations (RANS) [57]. Since the presence of this anomaly has been widely accepted, Pope published a correction term for round jets, but states its limitation to non-reacting test cases [58]. Furthermore, Smith et al. [57] showed that the information contained in the average- and RMS flow field is not sufficient for an adequate reconstruction of the round jet phenomenon. Improvement for the actual turbulent flame is expected by use of other turbulence models, like LES or Reynolds stress models (RSM). However, such work opens perspectives for the future but is beyond the scope of the present study. Nevertheless, the impact of inadequate turbulence modelling on other flame parameters has to be kept in mind when discussing those for the current numerical approach.

\subsubsection{Model validation: Soot}

Major target of the presented computation is the capability to predict soot volume fractions and mean particle diameters. The two dimensional images of the calculated and measured soot volume fraction are shown in Fig. 4c. Obviously, the differences in magnitude and shape are more pronounced than for the quantities discussed above. Both representations show the peak soot concentration on the centreline. While the simulation predicts the inception of soot formation mainly on the centreline and to a much lesser extent in the annular region, the experimental data clearly indicates early soot formation in the outer radial region at $\mathrm{r}=9 \mathrm{~mm}$ merging further downstream to centreline. It should be kept in mind that the instantaneous soot structures are spatially highly fluctuating and that these soot filament fluctuations increase with downstream location.

The axial profiles of the soot volume fraction displayed in Fig. 9a confirm the deviations between experimental and numerical values. The predicted soot formation starts too early in the flame, followed by a steep rise and a pronounced peak at $\mathrm{h}=122 \mathrm{~mm}$. The measured profile is smoother with a maximum at $\mathrm{h}=295 \mathrm{~mm}$. For the explanation of the too early peak in the simulation, the mean particle 
diameter shown in red is added to this plot. Particle growth occurs up to a height of about $300 \mathrm{~mm}$. Thereafter, the soot size freezes and even diminishes in regions further downstream due to oxidation before rising again. The biggest particles are present downstream of the location of maximum soot volume fraction. Given the small particle size early in the flame and the high soot concentration, the number density of those small particles appears to be at least one order of magnitude too high. So far, no measurements of particle sizes have been reported for this. However, comparison to experimental data from other flames, for example [59], indicates that the calculated mean particle diameters are in a reasonable range. The calculated initial peak in soot volume fraction along the axis is due to very small particles below 2-3 nm that may not be observed in the LII experiment, see discussion below.

As far as soot formation is concerned, soot oxidation is predicted too early based on the simulated soot volume fraction. Although the model fails to reproduce the location of initial soot formation, the soot concentration peak, and oxidation, it is surprising that the peak magnitude of soot volume fractions is in very good agreement. A deviation of one order of magnitude is frequently reported for this sensible parameter in literature. The maximum soot volume fraction in the experiment is $0.54 \mathrm{ppm}$, whereas the predicted value is $0.59 \mathrm{ppm}$.

Figure 9b displays a comparison of the radial profiles of soot volume fraction for four heights. While the experimental profiles at low heights show a pronounced annular shape, the simulation predicts initial soot formation in two co-annular rings at comparable magnitude. All calculated downstream profiles peak on the axis indicating that soot growth is significantly fed from the inner annulus as shown in Fig 4c. The measurements indicate main soot formation at the outer predicted annulus. In contrast to the temperature und axial velocity profiles, the experimental profiles are broader then in the calculation.

The deviations in the overall shape of the soot volume fraction distribution are most presumably correlated to the too early calculation of soot formation, since sensitive criteria of the jet flame like the lift-off height, temperature and velocity are in good or at least reasonable agreement. The predicted velocities are too low causing an early soot prediction. Beyond the impact of the turbulence model, potential reasons might link to inaccurate prediction of key precursor species in the soot formation model such as acetylene, toluene or benzene, but also to the soot model itself. For a more detailed understanding of these deviations, the following sections focus on the initial region of the flame and the early soot formation zone in detail. 


\subsection{Focused investigation of the early soot formation region}

\subsubsection{Pre-combustion analysis - Fuel/air mixing ratio}

Figure 10 displays the results for fuel distribution from the Raman scattering measurements in the region prior to combustion. The color plot in Fig. 10a compares the experimental data (left) and the computational result (right). The overall shape and dimensions are in good agreement. For example, the $30 \%$ iso-lines of the distributions are very close to each other, but the agreement diminishes for the regions of high fuel fraction. The experiment shows a strong decrease of fuel fraction on the centreline at $\mathrm{h}=7 \mathrm{~mm}$, whereas a comparable fuel fraction reduction does not occur before $\mathrm{h}=17 \mathrm{~mm}$ in the simulation. The impact of turbulence appears less pronounced and under predicted in the calculation. More quantitative information is contained in the radial and axial profile plots in Figs. 9b and 9c, respectively. Good agreement is identified for the first radial profile at $\mathrm{h}=4 \mathrm{~mm}$ in magnitude and width. Further downstream, the differences increase on the centreline, while the profile wings are in good agreement throughout. For the highest profile at $\mathrm{h}=20 \mathrm{~mm}$ the bias becomes smaller on the centreline. This is even more evident in Fig. 10c visualizing the axial profiles of the mixture ratios. Good agreement can be reported for the first $5 \mathrm{~mm}$ at $100 \%$ fuel and beyond $25 \mathrm{~mm}$ at approximately $40 \%$ fuel fraction. This confirms and quantifies the impression visible in the 2D plot; most probably, the model under predicts the fuel/air mixing in the pre-flame region due to an inaccurate turbulent mixing model used in the calculation to reduce the computational cost. This behaviour is commonly known for RANS methods, but is accepted due to the significant savings of computational time, which allows the CFD code to be applied to complex systems [60]. The question whether this simplification is acceptable for even more complex turbulent flames or not can only be answered in dependence of the case. It surely depends on available computer power and the accuracy requirements.

\subsubsection{Soot formation analysis}

Figure 11a shows the time-averaged $\mathrm{OH}$ concentration calculation (left) and measurements (right) for the lower part of the flame up to $120 \mathrm{~mm}$. The measured $\mathrm{OH}$ signal is only a qualitative measure and has been normalized to the maximum signal of $1600 \mathrm{ppm}$ from the predicted $\mathrm{OH}$ concentration for easier comparison. The images show a good agreement in shape and relative intensity distribution. Radial profiles of the $\mathrm{OH}$ concentration are displayed in Fig. 11b. The annular structure is clearly visible in experiment and simulation likewise; note the minor shift of the measured $\mathrm{OH}$ profiles to the left from centreline. $\mathrm{OH}$ production is predicted to start at $25 \mathrm{~mm}$, while experimental detection of $\mathrm{OH}$ starts at 
$23.5 \mathrm{~mm}$. Therefore, the radial profiles at $25 \mathrm{~mm}$ do not agree, although reasonable agreement can be seen for the profiles further downstream. Similar to the distribution of temperatures, the simulated profiles are displaced to higher radial values, here systematically by 1-2 $\mathrm{mm}$. Although the shape of the velocity profiles is different, a similar displacement was also observed there.

An important step in the chemical mechanism towards soot formation is the production of the soot precursors. The model employs a sectional approach with species above $100 \mathrm{amu}$ being divided into bins according to their mass. As mentioned earlier, PAHs are separated in three bins and soot is distributed over 25 bins, which are spaced logarithmically starting from $\operatorname{Bin}_{0}=800-1600$ amu up to 2.7 $10^{10} \mathrm{amu}$ (or $300 \mathrm{~nm}$ ) for the last bin. The PAHs measured by PLIF are roughly representative for the first $\mathrm{PAH}$ bin $\left(\mathrm{PAH}_{0}\right)$. Figure 12 shows the calculated $\mathrm{PAH}$ concentration (left) and measured (right) up to $120 \mathrm{~mm}$. Since no quantification was made for the LIF signal, the data is normalized to the maximum PAH signal present beyond $250 \mathrm{~mm}$ downstream of the fuel nozzle. A significant discrepancy between the predicted concentration peak at $90 \mathrm{~mm}$ and the steadily growing measured value up to around 275 $\mathrm{mm}$ (Fig. 2i) exists. Thus the general agreement is poor. The radial profiles at the same heights as those of $\mathrm{OH}$ are displayed in Fig. 12b. Again, the soot model predicts no PAHs at $\mathrm{h}=25 \mathrm{~mm}$. However, the annular structure seen in the measurements at $\mathrm{h}=30 \mathrm{~mm}$ is predicted by the calculation at this position. Further downstream in the flame, the experimental profiles become broader and the two branches of the projection merge, while the simulated profiles maintain the annular shape up to $75 \mathrm{~mm}$ and remain close to the centreline. Note the intensity scale is changing by one order of magnitude at $h=50 \mathrm{~mm}$, while both lower profile heights are zoomed in to show the bimodal structure more clearly. This PAH prediction is in contrast to the previous observations as they advance to the flame centre rather than the flame edge. Once again, the simplified treatment of the turbulence is most likely responsible for this difference. While all other measured flame quantities peak at larger radii in comparison to the experiment, the mixing and transport of particles and molecules appear under predicted for this turbulent system. However, the shape of the soot distributions (Fig. 4c) can be tracked all the way back to PAH distributions (Fig. 12a) and mixture fraction (Fig. 10a). Longer persistence of high mixture fractions in the simulation delays the formation of PAHs, while the local radial and vertical PAH predictions are responsible for a narrow flame axis centred soot distribution. The soot precursors are consumed by the soot formation process and are therefore not present in the far downstream region of the flame [61]. Measurements still show reasonable PAH concentrations in the upper flame region where the model does not predict any PAHs anymore. Previous model validations using laminar flames, 
(and not requiring turbulence-chemistry interaction) did not show this effect. Therefore, the chosen turbulence model appears to be the key element responsible for the observed discrepancies.

Beyond the comparison of measured and predicted quantities, a comparison of the spatial distributions of $\mathrm{OH}, \mathrm{PAH}$ and soot is informative. Note that both measurements were performed separately, so conclusions concerning temporal correlations cannot be drawn. Fig. 13 focuses on the inital region of the flame, i.e. the lowest laser sheet position showing signal for the quantities $\mathrm{OH}$, PAH and soot. On average (first row), the $\mathrm{OH}$ signatures (a) are characterized by thin and continuous tubular (or cylindrical) shape. The average PAH distribution (b) indicates formation in an annulus with the signatures merging on the axis after some millimeters. However, PAH peak intensities in the single shot images do not occur on the flame axis for this position in the flame (not shown). Figure 13c shows the time-averaged spatial correlation of both species. The images were binarized with the threshold value set at $10 \%$ of the peak intensity levels. This plot indicates PAH formation (green) about $2 \mathrm{~mm}$ downstream of $\mathrm{OH}$ (blue) at similar radial positions. The $\mathrm{OH}$ sheet encloses the PAH signature with some overlap (yellow). The initial PAH formation in the annular region is in contrast to the on-axis signal maximum found for the jet flame characterized by Lee et al. [52]. This difference is most probably due to the pilot flame used for stabilization in [52], influencing turbulent mixing, diffusion and chemistry. The soot average shown in (d) indicates formation several millimeters downstream of $\mathrm{OH}$ and $\mathrm{PAH}$. The radial peak overlaps with that of $\mathrm{OH}$ while some overlap with the $\mathrm{PAH}$ region and, even stronger, the region of unburned air outside the $\mathrm{OH}$ sheet is visible in plot (e) and profiles in Fig. 13h. A co-existence of $\mathrm{OH}$ and soot is hardly conceivable [62] and the overlap in the averaged images is probably the outcome of averaging spatially fluctuating distributions.

The second row of Fig. 13 displays examples of single shot images (not recorded simultaneously). Instantaneous $\mathrm{OH}$ images strongly resemble the time-averaged $\mathrm{OH}$ field, in most cases exhibiting relatively smooth shapes similar to that on the left side of the single-shot $\mathrm{OH}$ image (second row, a). Moderate wrinkling typically occurs, but location and thickness of the $\mathrm{OH}$ sheet are quite similar to the time-averaged image. Single shot PAH images (b) are much noisier due to low signal, yet all PAH single-shot images are well represented by the selected one with respect to shape and intensity. A superposition of the arbitrarily selected representations of $\mathrm{OH}$ and PAH (c) indicates only weak spatial overlap, equally valid for other arbitrarily selected pairs studied (not shown). So, spatial fluctuations of 
those species’ signatures are mainly responsible for the OH-PAH overlap visualized in upper row, plot (c).

While $\mathrm{OH}$ and $\mathrm{PAH}$ show quite similar spatial distribution in all single-shot images in their respective sequence, soot is only present in a limited number of images and its distribution exhibits a large variation in shape and location. Soot is formed close to the downstream end of this imaging region. Significant soot concentrations are spatially isolated and are detected in less than $30 \%$ of the single-shot measurements. Such soot concentrations can form in the central PAH zone, in the PAH-OH interface or even outside the $\mathrm{OH}$ sheet as seen in (f) and (g).

The presence of soot outside the time-averaged $\mathrm{OH}$ sheet is probably correlated to $\mathrm{OH}$ pockets forming occasionally. In such pockets, as visible in the right half of the single shot $\mathrm{OH}$ image in Fig.13a, the temperature and residence time are expected to be high, while strain rates are low [63]. Such conditions are favorable for soot formation [64]. Early soot formation seems to be significantly influenced by instantaneous species distributions and the surrounding flow field like those in the $\mathrm{OH}$ pockets. Therefore, a simultaneous measurement of flow field and species distributions is highly desirable for future studies. Due to the non-simultaneous measurements in our case only statistical considerations are possible. In addition, LES-based studies designed to capture the above described instantaneous distributions and the resulting time-averaged combustion behavior would be of great help.

\subsubsection{Applications and discussion of the soot model}

The THETA code with implemented soot model has been designed to predict soot for a variety of fuels at relatively low computational costs. Application of the model to simple test systems have been presented before [15] and delivered an exceptionally good agreement between simulation and experiment. Compared to other works [8-9,19-20], the present soot model is less detailed, but achieves comparable results [15]. The benefit of the presented reduced soot model is its feasibility to be applied to more complex problems, i.e. gas turbine combustion.

The presented numerical solution required two weeks for the simulation on 32 Intel Xenon CPUs, which is considered a low computational effort for such a turbulent model system. Limitations in the handling of such a complex system are undoubtfully present and are mainly attributed to the turbulence and its treatment. Generally, turbulence introduces three significant challenges:

The first one is the handling of larger grids to resolve very small structures compared to the overall length of the flame; this results in a relevant increase in computational time. Computations are often limited to smaller sections of the complete flame. 
The second challenge is the modelling of the turbulence itself. In order to reduce the computational cost, the present CFD and soot model uses Reynolds-averaged transport equations that are known for having deficits in respect to turbulent jet flows [57]. However, the detailed analysis shown here points out the relevance of the turbulence model for the studied turbulent jet. Therefore, future optimization will introduce LES to improve the turbulence prediction.

The third main challenge, the turbulence-chemistry-interaction, is also the most complex aspect in the modelling of turbulent flames. The present CFD implementation uses a multivariate assumed-PDF approach providing reasonable results. The main advantage of this approach is the reduction of computational time since temperature and species probability distributions are pre-defined. Additionally, all species fluctuations are assumed to be similar. Since this assumption cannot be drawn for soot, fluctuations of soot are neglected, resulting in the early soot maximum predicted by simulation (Fig. 4c). A transported-PDF-approach, currently under development for implementation into the presented THETA code, is expected to be a major step forward in describing such a complex system more accurately.

Although there is still room for improvement and model-tuning, the present CFD code is applicable to complex combustion systems. The THETA code with implemented soot model is able to calculate the studied lifted turbulent flame with good agreement of the global flame parameters at reasonable computational effort. In addition, the implementation of numerous soot bins allows for prediction of the mean soot particle diameter and the number density; two dimensional plots complementing Fig. 9a are shown in Fig. 14. Up to now, no experimental data on particle size has been available; particle diameters and their fluctuation are clearly required for validation purposes and shall allow for further model improvements.

Calculated mean soot particle diameters are presented in Fig. 14a. Their growth proceeds up to a height of about $250 \mathrm{~mm}$ while the spatial distribution of the profile is significantly wider compared to the soot volume fraction (Fig. 4c).

The number density shown in Fig. 14b reflects the impact of soot formation, coagulation, and oxidation. In the rich hot zones of the lower part of the flame a large number of very small soot particles are formed resulting in a steep rise of soot number density, almost coincident with the presence of first $\mathrm{PAH}$ bin $_{0}$ species (Fig. 12). This indicates the fast transition through the PAH bins and PAH consumption is too rapid. As coagulation reactions become more important and start to overwhelm particle formation, the number density diminishes. Finally, at the end of the flame where additional air 
advection turns the local conditions lean, soot oxidation causes a sudden drop in number density. Keeping in mind that soot volume fraction is derived as convolution of the third power of particle diameter (left plot) with the number density (right plot), it becomes clear that the overlap of both plots roughly defines the shape visualized in Fig. 4c, dominated by the log-plotted particle number.

The measured soot volume fraction distribution follows the calculated diameter distribution. This may reflect a discrepancy in definition of the term soot, specifically the definition of the transition from PAH into soot bins as implemented in the model versus the smallest particle size measureable by LII or other diagnostic techniques. The LII technique relies on mean photon absorption of approximately black and non-volatile matter and is insensitive to large molecular-scale species, barely large enough to be called particles. The smallest soot bin at $800 \mathrm{amu}$ (about $1 \mathrm{~nm}$ ) may be composed of species similar to bilayered ovalene which is certainly not excited by typical LII photons. Even a quadruple-layer of this type of molecule or a similar agglomeration of aromatic species from this size range, belonging to soot bin $_{1}$ probably does not generate measureable LII-signal.

The lowest reported soot particle sizes derived from LII measurements are in the range of 2-3 nm [65]. Other diagnostics, such as Engine Exhaust Particle Sizers (EEPS) or Scanning Mobility Particle Sizers (SMPS) are able to measure down to $3 \mathrm{~nm}$ [66]. Differential Mobility Analyzers (DMA) can even measure below that [67]. However, the detection of particles (or droplets) in this size range frequently includes volatiles that are not representative of real soot. Clearly, even minor differences in the definition of the term soot (e.g. particle diameter, mass or broad-band light absorptivity) sensitively affect the comparison of simulation and experiment. As the smallest soot bins account for huge particle numbers low in the flame, our conclusion from this comparison is that a more reasonable threshold for the transition from PAH to measurable, non-volatile soot is at approximately $2 \mathrm{~nm}$ or 3200-4000 amu. This definition should significantly improve the agreement of the calculated with the LII derived soot distribution. The analysis creates the demand for measured particle sizes that are expected to support further model optimization. However, even in the current numerical approach, general applicability of the THETA code to complex sooting flames is demonstrated when achievable accuracy is considered.

\section{Summary and conclusions}

The existing database of a sooting turbulent jet flame, specifically designed for the evaluation of soot models, was expanded by the application of the PLIF and Raman technique. In a previous publication we reported on the measurement of temperature by SV-CARS, the velocity by PIV and soot concentration by LII [24]. In the present work, complementary data of $\mathrm{OH}$ and PAH distributions have 
been added to the validation database. Additional Raman measurements were performed to characterize the mixture ratio in the pre-flame region.

The database was used for validation of the in-house CFD THETA-code with an implemented novel soot model. This numerical approach introduces a reduced chemical soot mechanism into a combustion code, capable of predicting soot volume fraction, mean particle diameter and number density for complex systems. The model was designed to predict soot for a variety of fuels with good accuracy at relatively low computational costs. Comparison of the model and the experimental database shows good agreement for velocities, temperatures und $\mathrm{OH}$ distributions. Especially the sensitive lift-off height is predicted notably well. Lesser agreement is found for PAHs and soot distributions. Although the global magnitude of soot volume fractions is in good agreement, the shape and spatial distributions show distinct differences compared to the measured results. Since model validation using laminar flames has been successful [15] and the general applicability of the model to those sooting flames was demonstrated. The major deviations of soot distributions, fuel/air mixing as well as smaller disagreement for other parameters used for validation are attributed to the relatively simple turbulence model [60]. Future optimization will include LES for more realistic modelling of the transient turbulent structures. However, if technical applicability is achievable with the LES approach, still needs to be proven. Considering the complexity of this flame and its relatively large size, the level of agreement derived for most quantities is quite promising. The included assumed PDF approach represents an attractive alternative to more detailed models such as transported PDF methods, for example.

A sensitive issue for the comparison of soot distributions is a generally accepted definition of the term soot, specifically for its smaller size. Assignment of one or two bins can have significant impact on the resulting particle number distributions and soot volume fraction due to the extremely large numbers of very small "particles". Part of the disagreement determined for soot concentrations is attributed to different threshold sizes. The LII technique performs poorly for molecule-like species (forming the majority of particles below $2 \mathrm{~nm}$ ) while the model defines soot as everything larger than $800 \mathrm{amu}$. 


\section{Acknowledgements}

This research was supported by the Helmholtz/NRC collaborative partnership "Fuelling a cleaner future: Quantification and characterization of soot emissions from combustion based energy conversion”. The authors wish to thank Thomas Mosbach and Claudio Dem for their valuable contributions in data analysis and last, but not least Peter Ess for fruitful and insightful discussions. 


\section{References}

[1] A. Petzold, R. Marsh, M. Johnson, M. Miller, Y. Sevcenco, D. Delhaye, X. Vancassel, A. Ibrahim, A. Veira, P. Williams, H. Bauer, A. Crayford, S. Morris, P. Kay, P. Bowen, W. D. Bachalo, D. Raper, Final Report, EASA.2008.OP.13, EASA Cologne (2009).

[2] R.B. Schlesinger, N. Kunzli, G.M. Hidy, T. Gotschi, M. Jerret, Inhalation Toxic 18 (2006) 95125.

[3] W. Lazik, T. Doerr, S. Bake, R. von der Bank, L. Rackwitz, Proc. ASME Turbo Expo 2008, Berlin, Paper GT2008-51115.

[4] T. R. Barfknecht, Progr. Energ. Combust. Sci. 9 (1983) 199-237.

[5] E. J. Jensen, O. B. Toon, Nucleation and Atmospheric Aerosols (1996) 848-851.

[6] D.O. Lignell, J.H. Chen, P.J. Smith, Combust. Flame 155 (2008) 316-333.

[7] M. Di Domenico, P. Gerlinger, M. Aigner, Combust. Flame 157 (2010) 246-258.

[8] H. Richter, M. Braun-Unkhoff, S. Granata, J. Yu, E. Goos, N. Slavinskaya, P. Frank, W. Green, J. Howard, Proc. European Combustion Meeting ECM 2005, Louvain-la-Neuve, Belgium, Paper 163.

[9] S. B. Dworkin, Q. Zhang, M. J. Thomson, N.A. Slavinskaya, U. Riedel, Combust. Flame 158 (2011) 1682-1695.

[10] N. Slavinskaya, P. Frank, Combust. Flame 156 (2009) 1705-1720.

[11] T. Chittipotula, G. Janiga, D. Thevenin, Proc. Combust. Inst. 33 (2011) 559-567.

[12] I. Kennedy, Prog. Energy Combust. Sci. 23 (1997) 95-132. 
[13] M. Balthasar, M. Frenklach, Combust. Flame 140 (2005) 130-145.

[14] C.K. Westbrook, W.J. Pitz, O. Herbinet, H.J. Curran, E.J. Silke, Combust. Flame 156 (2009) 181-199.

[15] T. Blacha, M. Di Domenico, P. Gerlinger, M. Aigner, Combust. Flame, (2011) in press (DOI:10.1016/j.combustflame.2011.07.006).

[16] J.B. Moss, I.M. Aksit, Proc. Combust. Inst. 31 (2007) 3139-3146.

[17] S. Niksa, G.S. Liu, Proc. Combust. Inst. 29 (2002) 2259-2265.

[18] H. Barths, N. Peters, N. Brehm, A. Mack, M. Pfitzner, V. Smiljanovski, Proc. Combust. Inst. 27 (1998), 1841-1847.

[19] A. D’Anna, J.H. Kent, Combust. Flame, 152 (2008), 573-587.

[20] I.I. Naydenova, Ph.D. thesis, Rupertus Carola University, Heidelberg, Germany, 2007.

[21] M. Frenklach, H. Wang, Proc. Combust. Inst. 23 (1990), 1559-1566.

[22] F. Bisetti, G. Blanquart, M.E. Mueller, H. Pitsch, Combust. Flame (2011), in press (DOI:10.1016/j.combustflame.2011.05.021).

[23] N. Slavinskaya, O. Haidn, Proc. ASME Turbo Expo 2008, Berlin, Paper GT2008-1012.

[24] M. Köhler, K. P. Geigle, W. Meier, B. M. Crosland, K. A. Thomson, G. J. Smallwood, Appl. Phys. B 104 (2011) 409-425.

[25] L. Wehr, W. Meier, P. Kutne, C. Hassa, Proc. Combust. Inst. 31 (2007) 3099-3106.

[26] A.R. Masri, R.W. Dibble, R.S. Barlow, Prog. Energy Combust. Sci. 22 (1996) 307-362. 
[27] A.C. Eckbreth, Laser Diagnostic for Combustion Temperature and Species, $2^{\text {nd }}$ edition, Gordon and Breach, Amsterdam (1996).

[28] R.S. Barlow, C.D. Carter, R.W. Pitz, in: K. Kohse-Höinghaus and J. Jeffries (Eds), Applied Combustion Diagnostics, Taylor \& Francis, New York (2002).

[29] P. Kutne, B.K. Kapadia, W. Meier, M. Aigner, Proc. Combust. Inst. 33 (2011) 3383-3390.

[30] M. Köhler, I. Boxx, K.P. Geigle, W. Meier, Appl. Phys. B 103 (2011) 271-279.

[31] J. Luque, D. Crosley, LIFBASE: Database and spectral simulation program (version 2.0.6), Report MP 99-009, SRI International, Menlo Park, Calif. (1999).

[32] W. Meier, R.S. Barlow, Y.-L. Chen, J.-Y. Chen, Combust. Flame, 123 (2000) 326-343.

[33] J. Zerbs, K.P. Geigle, O. Lammel, J. Hader, R. Stirn, R. Hadef, W. Meier, Appl. Phys. B 96 (2009) 683-694.

[34] T.T. Charalampopoulos, J.D. Felske, Combust. Flame 68 (1987) 283-294.

[35] M. Di Domenico P. Gerlinger, M. Aigner, AIAA2006-1163 (2006).

[36] E. Ivanova, B.E. Noll, M. Aigner, Proc. 40th AIAA Fluid Dynamics Conference and Exhibit 2010, Chicago, USA, Paper AIAA-2010-4724.

[37] W.P. Jones, B.E. Launder, Int. J. Heat Mass Transfer 15 (1972) 301-314.

[38] P. Gerlinger, Numerische Verbrennungssimulation, Effiziente numerische Simulation turbulenter Verbrennung, Springer, 1. ed., Berlin (2006).

[39] P. Gerlinger, B. Noll, M. Aigner, Progr. Comput. Fluid Dynam. 5 (2005) 334-344. 
[40] P. Gerlinger, Comb. Sci. Tech. 175 (2003) 841-872.

[41] P. Gerlinger, H. Möbus, D. Brüggemann, J. Comput. Phys. 167 (2001) 247-276.

[42] M. Di Domenico, Ph.D. thesis, University of Stuttgart, Germany, 2008.

[43] S.S. Girimaji, Comb. Sci. Tech. 78 (1991) 177-196.

[44] S.S. Girimaji, AIAA paper 91-1792 (1991).

[45] F. Mauß, Ph.D. thesis, Rheinisch-Westfälisch Technische Hochschule Aachen, Germany, (1998).

[46] T. Blacha, M. Di Domenico, M. Köhler, P. Gerlinger, M. Aigner, AIAA 2011-114 (2011).

[47] C.L. Lubbers, G. Brethouwer, B.J. Boersma, Fluid Dynamics Research 28 (2001) 189-208.

[48] V. Bergmann, W. Meier, D. Wolff, W. Stricker, Appl. Phys. B 66 (1998) 489-502.

[49] I. Boxx, M. Stöhr, C. Carter, W. Meier, Appl. Phys. B 95 (2009) 23-29.

[50] K. Hayashida, K. Amagai, K. Satoh, M. Arai, Journal of Engineering for Gas Turbines and Power 128 (2006) 241-246.

[51] I.B. Berlman, Handbook of Fluorescence Spectra of Aromatic Molecules, Academic Press, New York (1965).

[52] S.-Y. Lee, S.R. Turns, R.J. Santoro, Combust. Flame 156 (2009) 2264-2275.

[53] A. Habibi, B. Merci, G.J. Heynderickx, Comput. Chem. Eng. 31, 1389-1406 (2007).

[54] M.F. Modest, Radiative Heat Transfer, Acedemic, New York, 2nd (2003). 
[55] M. Ravishankar, S. Mazumder, A. Kumar, J. Heat Tran. (2010) 1-14.

[56] F. Liu, H. Guo, G.J. Smallwood, Ö.L. Gülder, J. Quant. Spectrosc. Ra., 73 (2002) 409-421.

[57] E.J. Smith, G.J. Nathan, B.B. Dally, $15^{\text {th }}$ Australasian Fluid Mechanics Conference, Sydney (2004).

[58] S.B. Pope, AIAA Journal 16 (1978) 279-281.

[59] S. Will, S. Schraml, A. Leipertz, Proc. Combust. Inst. 26 (1996) 2277-2284.

[60] E. Ivanova, B. Noll, M. Aigner, 6th AIAA Theoretical Fluid Mechanics Conference, Honolulu, Hawaii, June 27-30, 2011, Paper AIAA-2011-3934.

[61] H. Richter, J.B. Howard, PCCP 4 (2002) 2038-2055.

[62] T.R. Meyer, S. Roy, V.M. Belovich, E. Corporan, J.R. Gord, Appl. Opt. 44 (2005) 445-454.

[63] J. Hult, U. Meier, W. Meier, A. Harvey, C.F. Kaminski, Proc. Combust. Inst. 30 (2005) 701-709.

[64] M. E. Decroix, W. L. Roberts, Combust. Sci. Technol. 160 (2000) 165-189.

[65] A. Eremin, E. Gurentsov, M. Hofmann, B.F. Kock, C. Schulz, Appl. Phys. B 83 (2006) 449-454.

[66] R. Stirn, T. Gonzalez Baquet, S. Kanjarkar, W. Meier, K.P. Geigle, H.H. Grotheer, C. Wahl, M. Aigner, Combust. Sci. Technol. 181 (2009) 329-349.

[67] L.A. Sgro, A.C. Barone, M. Commodo, A. D’Alessio, A. De Filippo, G. Lanzuolo, P. Minutolo, Proc. Combust. Inst. 32 (2009) 689-696. 


\section{Captions}

Figure 1: a) Experimental setup for OH-PLIF and PAH-PLIF measurements. b) Optical setup for the single-shot Raman measurements.

Figure 2: False color images: a) Representative random collection of instantaneous LII images (field of view $39.9 \times 112.5 \mathrm{~mm}$ ). The maximum soot concentration of $4.5 \mathrm{ppm}$ is valid for this random set. b) RMS for the averaged LII image. c) Averaged 2D-LII over 1000 single images with a maximum averaged soot volume fraction of $0.54 \mathrm{ppm}$. d) Representative random collection of instantaneous $\mathrm{OH}$ images (field of view 43.9 x $108.8 \mathrm{~mm}$ ) with e) corresponding RMS and f) averaged 2D-PLIF images. g) Representative random collection of instantaneous PAH images (field of view 43.9 x $108.8 \mathrm{~mm}$ ) with h) corresponding RMS and i) averaged 2D-PLIF images.

Figure 3: Experimental results from Raman measurements. Interpolated two dimensional plots are shown for a) fuel mole fraction averaged over 400 single shots and b) the corresponding RMS of fuel mole fraction.

Figure 4: Calculated quantities of the complete flame (left side) and corresponding experimental data (right side). Two dimensional contour plots are shown for a) averaged temperature, b) averaged axial velocity and c) soot volume fraction.

Figure 5: Determination of the level of fluctuation in the lift-off height. a) Typical instantaneous $\mathrm{OH}$ image used for analysis. b) Axial concentration profiles of the left and right $\mathrm{OH}$ image branch. Flame islands are ignored by the analysis and only the steep concentration gradient is used. c) Statistics over 500 images resulting in a Gaussian type distribution of the lift-off height.

Figure 6: Comparison of the simulated temperature profiles with the experimental values: a) Axial profiles; b) Radial profiles at $\mathrm{h}=63 \mathrm{~mm}$; c) Radial profiles at $\mathrm{h}=113 \mathrm{~mm}$; d) Radial profiles at $\mathrm{h}=213$ mm. Mean $\left(\mathrm{T}_{\text {mean }}\right)$ and most probable $\left(\mathrm{T}_{\text {mopro }}\right)$ temperatures are shown and compared to the simulated averaged temperatures (line). The temperature distribution is indicated by the grey band (simulation) and y-bars (experiment). The x-bar in the radial profiles is only valid for the single outer point obtained from the additional Raman measurements and represents the maximum assumed error of the radial distance from the flame axis. 
Figure 7: Experimental probability density function (pdf) for selected heights above the burner with the total number of events for each measurement. The red line represents a fitted Gaussian curve to the data points.

Figure 8: Comparison of the simulated and measured profiles of the mean axial velocities: a) Axial profiles; b) Radial profiles for selected heights.

Figure 9: Comparison of the simulated and measured profile of the soot volume fraction: a) Axial profiles for the mean soot volume fraction and simulated mean particle diameter $d_{p}$; b) Radial profiles for selected heights.

Figure 10: Comparison of measured and simulated fuel mole fraction in the start region of the jet. Color plot is shown for a) the experimental (left) and simulated (right) mixture fraction of ethylene. b) Radial profiles for selected heights with experimental error bars. c) Axial profiles.

Figure 11: Comparison of measured and simulated $\mathrm{OH}$ distributions with focus on the lift-off region. Color plot is shown for a) the simulated (left) and experimental (right, relative intensity) $\mathrm{OH}$ concentration. Note that the experimental data is slightly shifted from centreline. b) Radial profiles for selected heights.

Figure 12: Comparison of measured and simulated PAH distributions with focus on the lift-off region. Color plot is shown for a) the experimental qualitative PAH fluorescence (right) and simulated (left) PAH concentration; displayed is the first simulated bin $\mathrm{PAH}_{0}$. b) Radial profiles for selected heights; note the different axis scales.

Figure 13: Spatial distributions and overlap of $\mathrm{OH}, \mathrm{PAH}$ and soot on time-average (upper row) and instantaneously (second row). a) OH-PLIF, b) PAH-PLIF, c) binarized image pairs of OH (blue) and PAH (green) - the overlap of both is displayed in yellow, d) LII, e) LII signature (orange) merged into c). The third row displays two more LII single shot events relative to the time-averaged f) $\mathrm{OH}$ and g) $\mathrm{PAH}$ distribution. The profile plot $\mathrm{h}$ ) on the right visualizes the horizontal time-averaged soot distribution at $\mathrm{h}=25 \mathrm{~mm}$ relative to $\mathrm{OH}$ and $\mathrm{PAH}$ as taken from the upper row.

Figure 14: Simulated soot properties. Two dimensional color plots are shown for a) mean particle diameter $\mathrm{d}_{\mathrm{p}}$ and $\mathrm{b}$ ) soot number density $\mathrm{N}_{\mathrm{S}}$. 


\section{List of Figures}

Figure 1: a) Experimental setup for OH-PLIF and PAH-PLIF measurements. b) Optical setup for the single-shot Raman measurements.

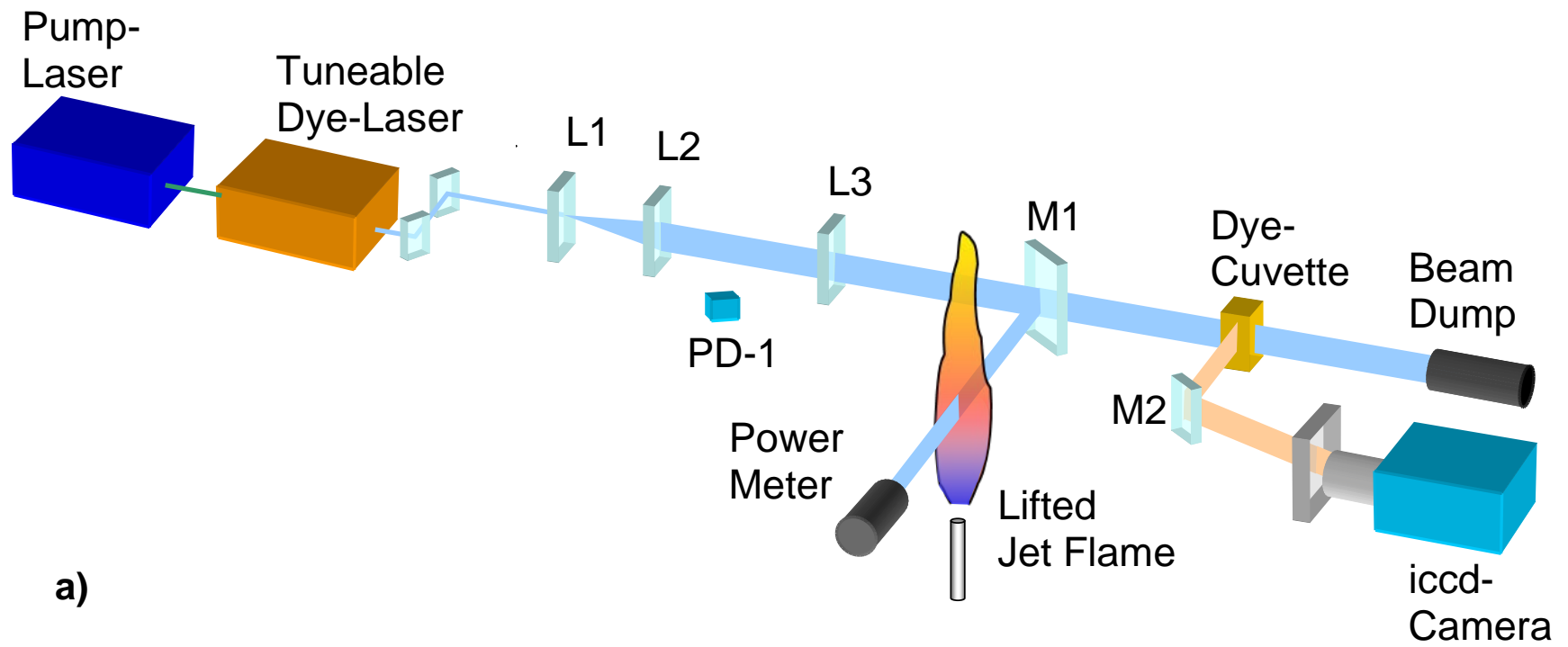

Flashlamp-Dye-

Laser $489 \mathrm{~nm}$

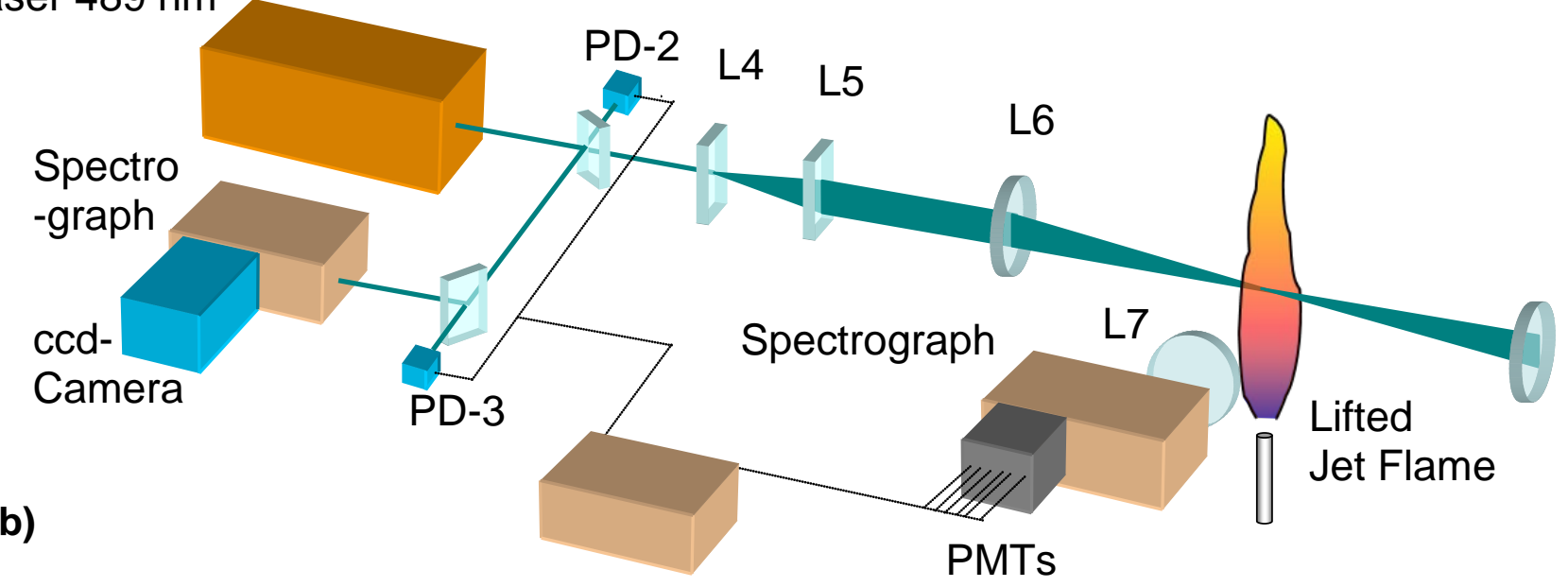


Figure 2: False color images: a) Representative random collection of instantaneous LII images (field of view $39.9 \times 112.5 \mathrm{~mm}$ ). The maximum soot concentration of $4.5 \mathrm{ppm}$ is valid for this random set. b) RMS for the averaged LII image. c) Averaged 2D-LII over 1000 single images with a maximum averaged soot volume fraction of $0.54 \mathrm{ppm}$. d) Representative random collection of instantaneous $\mathrm{OH}$ images (field of view 43.9 x $108.8 \mathrm{~mm}$ ) with e) corresponding RMS and f) averaged 2D-PLIF images.

g) Representative random collection of instantaneous PAH images (field of view 43.9 x $108.8 \mathrm{~mm}$ ) with h) corresponding RMS and i) averaged 2D-PLIF images.

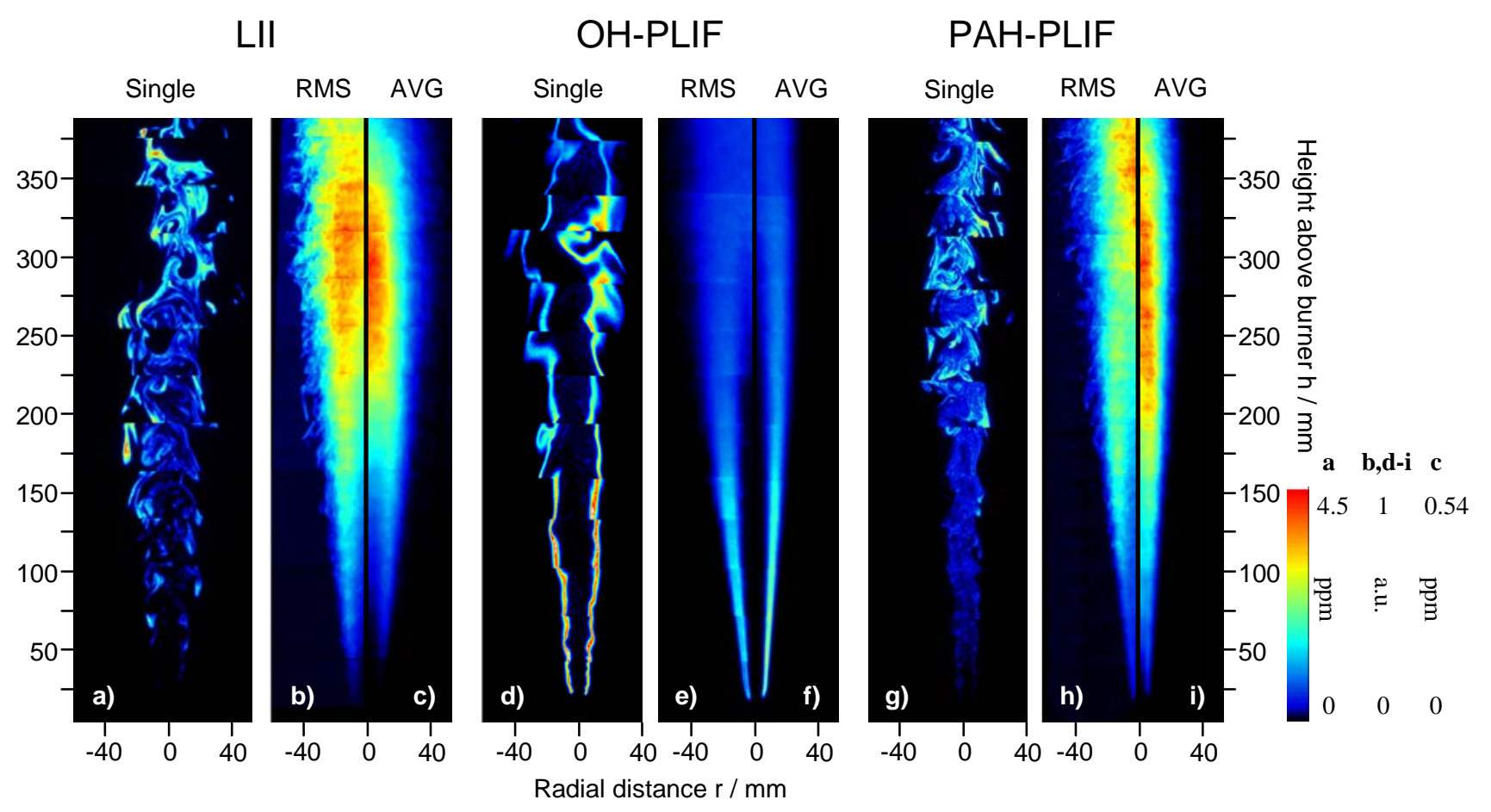


Figure 3: Experimental results from Raman measurements. Interpolated two dimensional plots are shown for a) fuel mole fraction averaged over 400 single shots and b) the corresponding RMS of fuel mole fraction.

a)

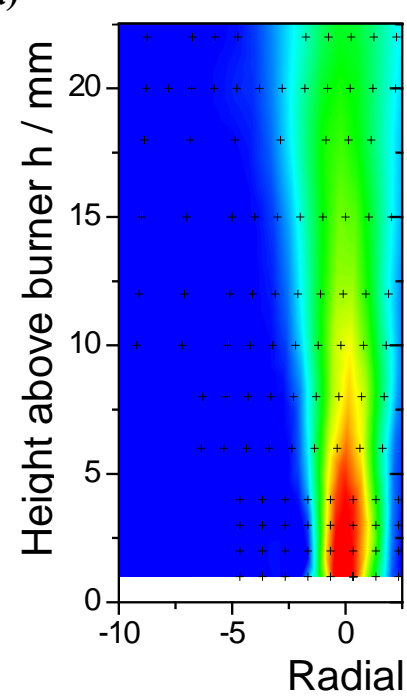

b)

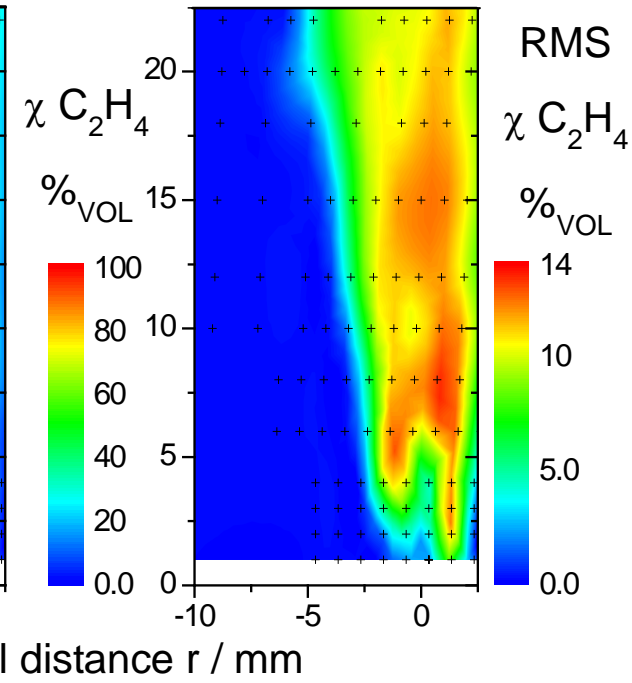


Figure 4: Calculated quantities of the complete flame (left side) and corresponding experimental data (right side). Two dimensional contour plots are shown for a) averaged temperature, b) averaged axial velocity and c) soot volume fraction.

a) Temperature

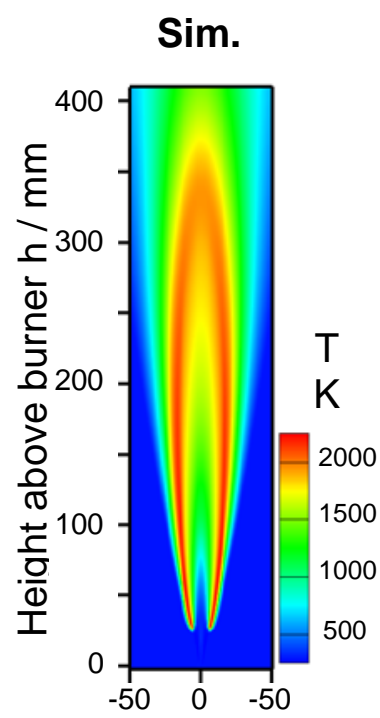

Radial distance $\mathrm{r} / \mathrm{mm}$ b)

Velocity

Sim.

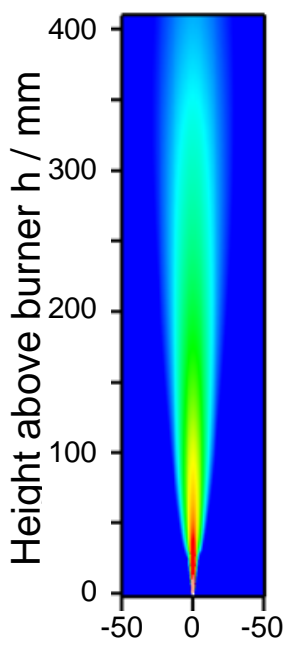

Exp.

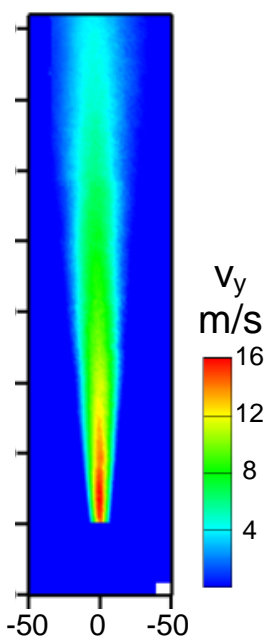

Radial distance $r / \mathrm{mm}$ c) Soot

Sim. Exp.

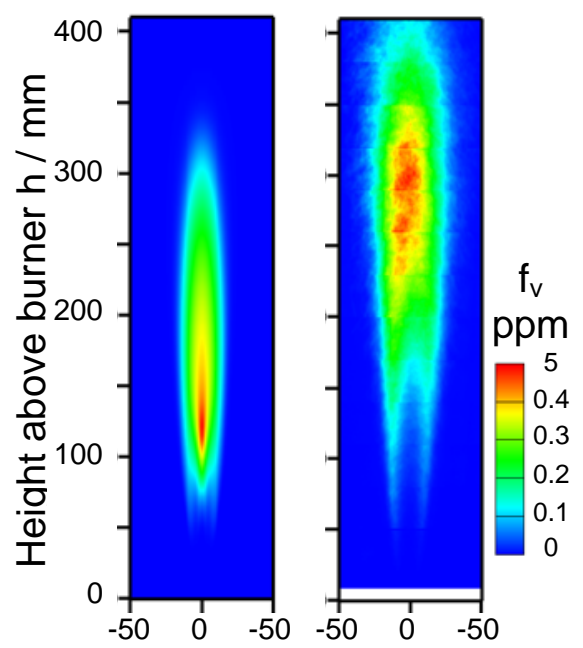

Radial distance $\mathrm{r} / \mathrm{mm}$ 
Figure 5: Determination of the level of fluctuation in the lift-off height. a) Typical instantaneous $\mathrm{OH}$ image used for analysis. b) Axial concentration profiles of the left and right $\mathrm{OH}$ image branch. Flame islands are ignored by the analysis and only the steep concentration gradient is used. c) Statistics over 500 images resulting in a Gaussian type distribution of the lift-off height.

a)

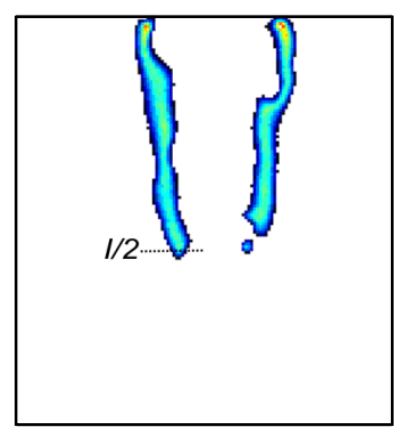

b)

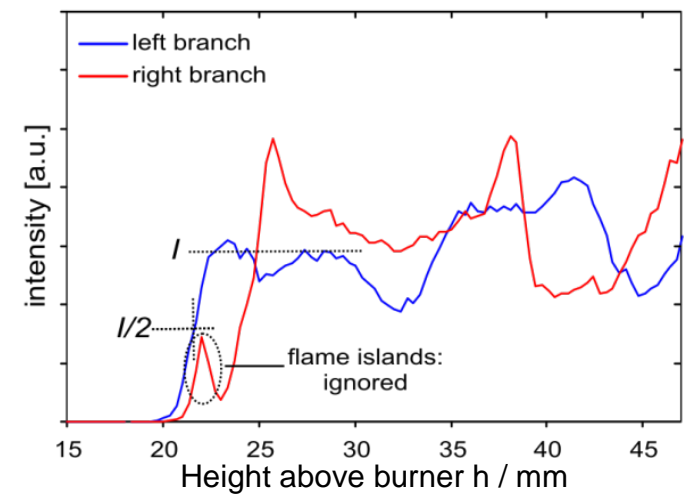

c)

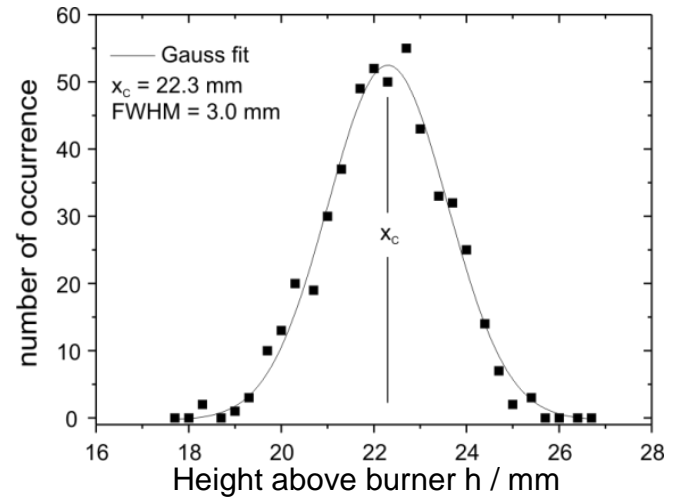


Figure 6: Comparison of the simulated temperature profiles with the experimental values: a) Axial profiles; b) Radial profiles at $\mathrm{h}=63 \mathrm{~mm}$; c) Radial profiles at $\mathrm{h}=113 \mathrm{~mm}$; d) Radial profiles at $\mathrm{h}=213$ mm. Mean $\left(\mathrm{T}_{\text {mean }}\right)$ and most probable $\left(\mathrm{T}_{\text {mopro }}\right)$ temperatures are shown and compared to the simulated averaged temperatures (line). The temperature distribution is indicated by the grey band (simulation) and y-bars (experiment). The x-bar in the radial profiles is only valid for the single outer point obtained from the additional Raman measurements and represents the maximum assumed error of the radial distance from the flame axis.
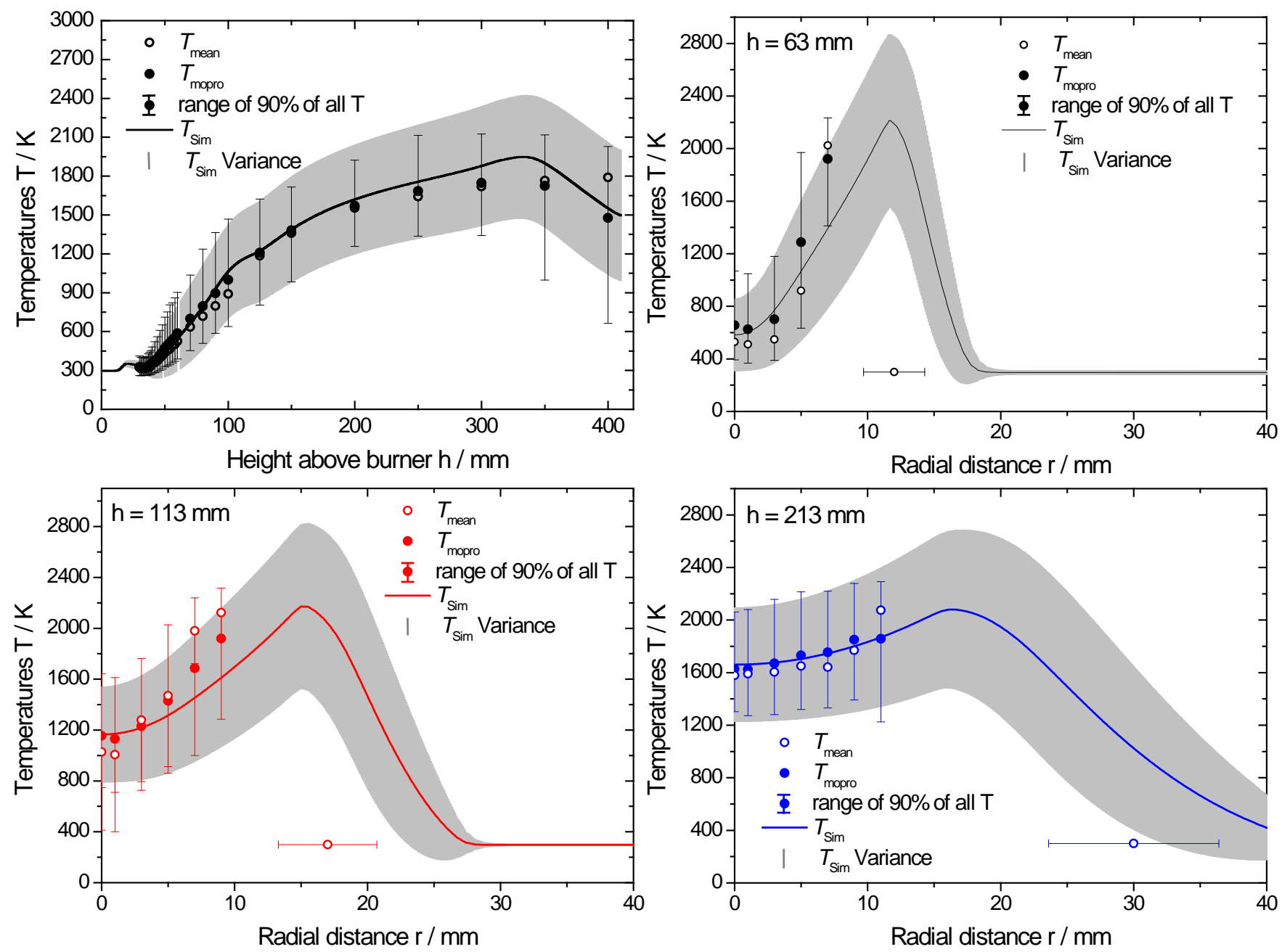
Figure 7: Experimental probability density function (pdf) for selected heights above the burner with the total number of events for each measurement. The red line represents a fitted Gaussian curve to the data points.
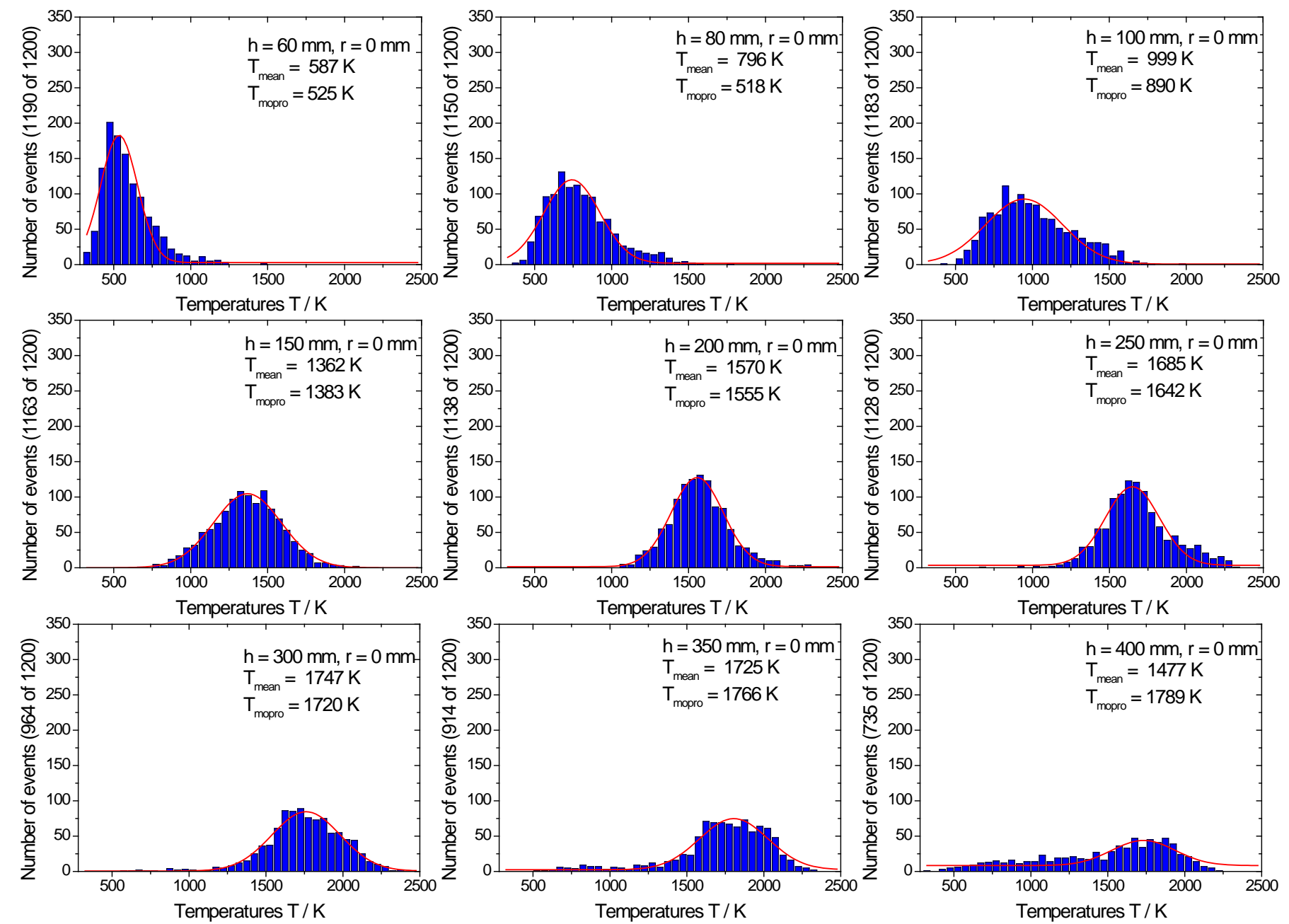
Figure 8: Comparison of the simulated and measured profiles of the mean axial velocities: a) Axial profiles; b) Radial profiles for selected heights.
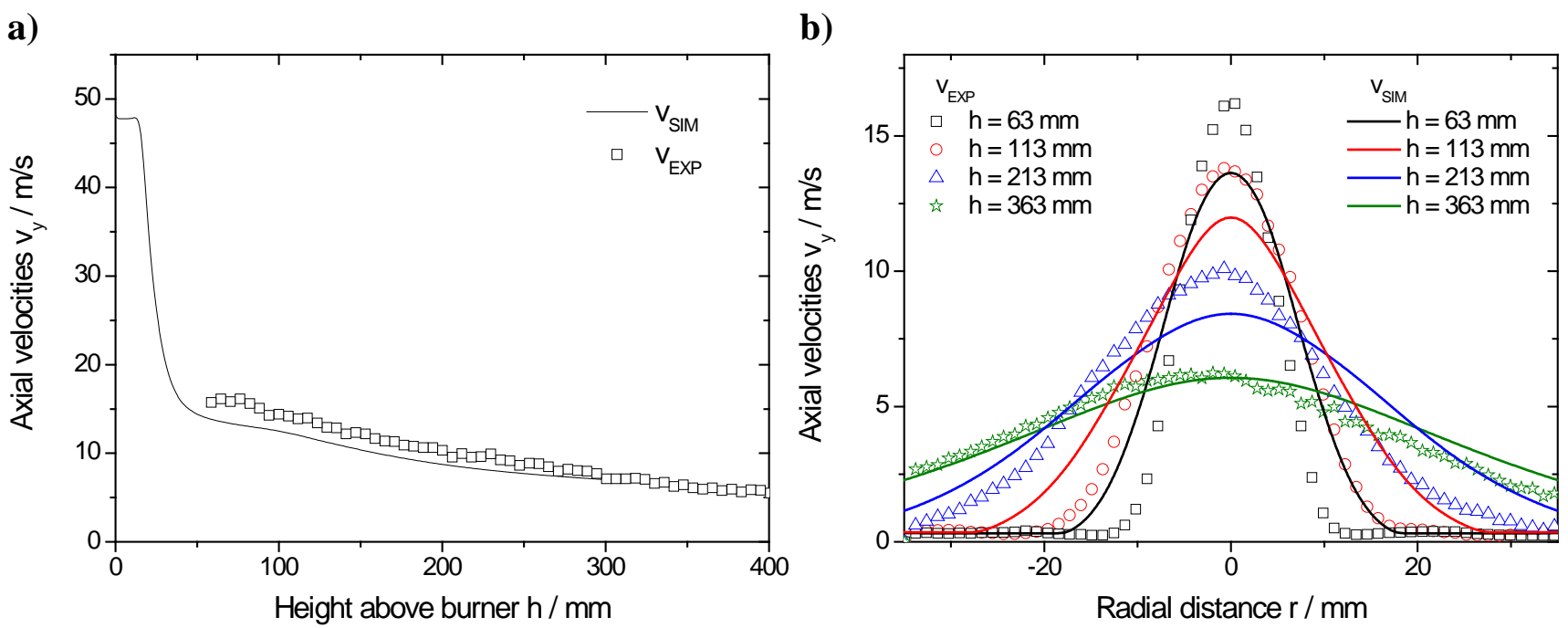
Figure 9: Comparison of the simulated and measured profile of the soot volume fraction: a) Axial profiles for the mean soot volume fraction and simulated mean particle diameter $d_{p}$; b) Radial profiles for selected heights.

a)

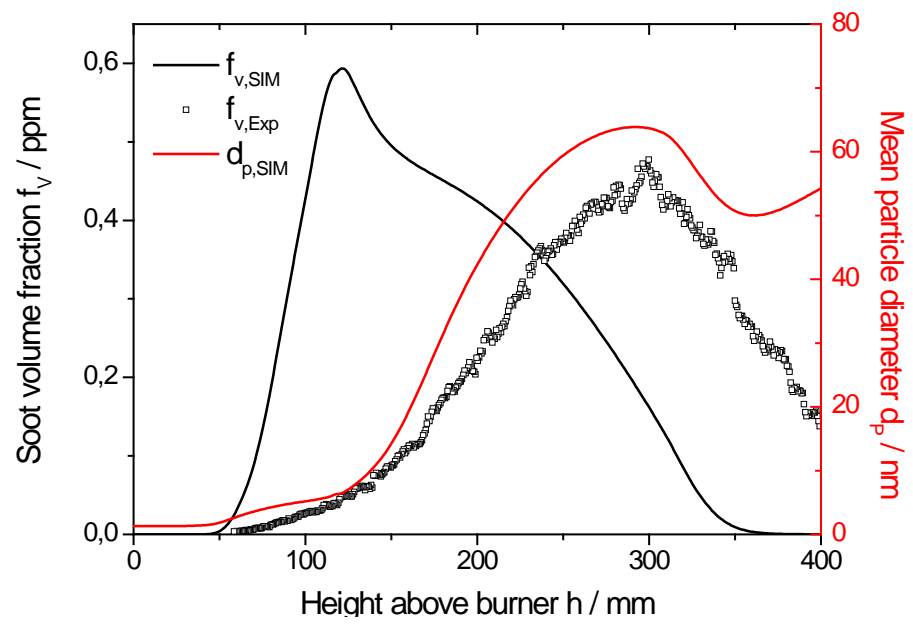

b)

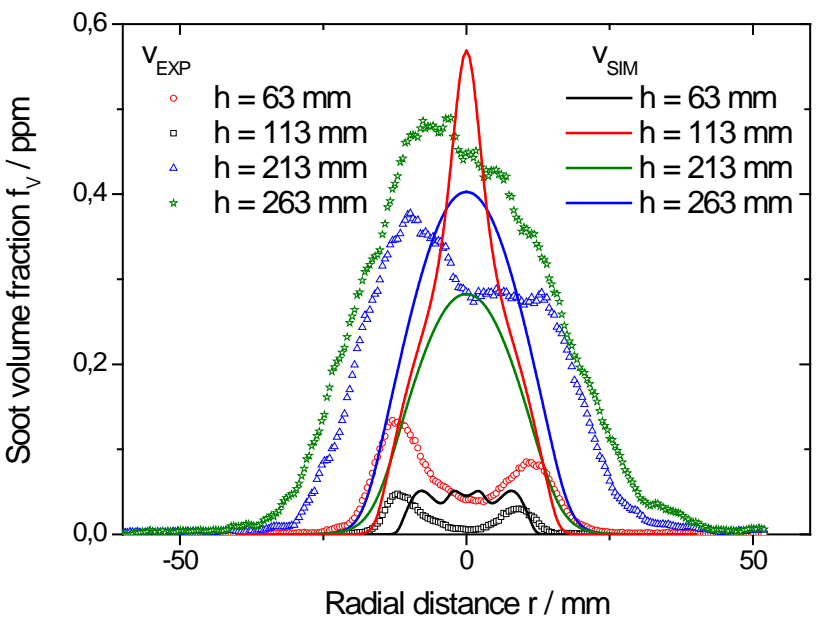


Figure 10: Comparison of measured and simulated fuel mole fraction in the start region of the jet. Color plot is shown for a) the experimental (left) and simulated (right) mixture fraction of ethylene. b) Radial profiles for selected heights with experimental error bars. c) Axial profiles.

a)

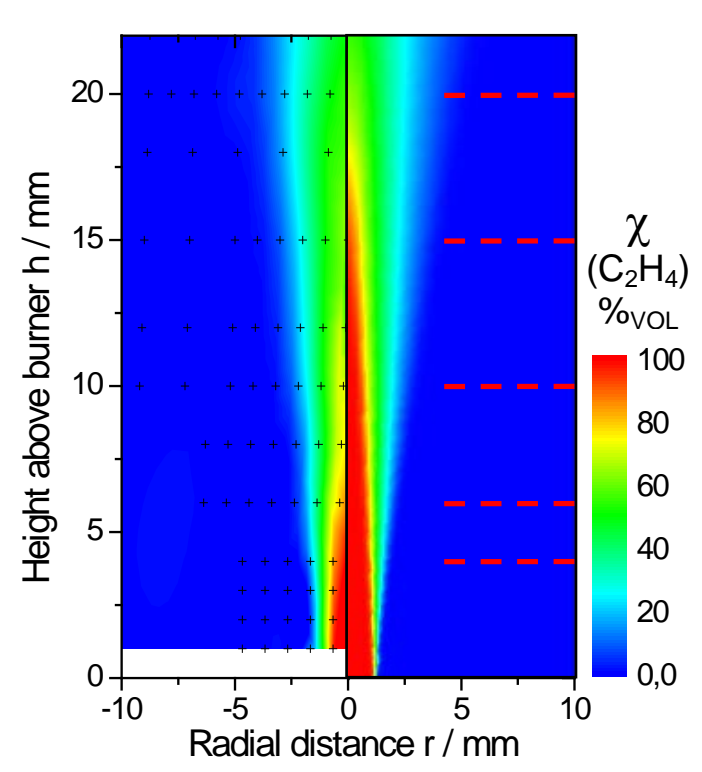

b)

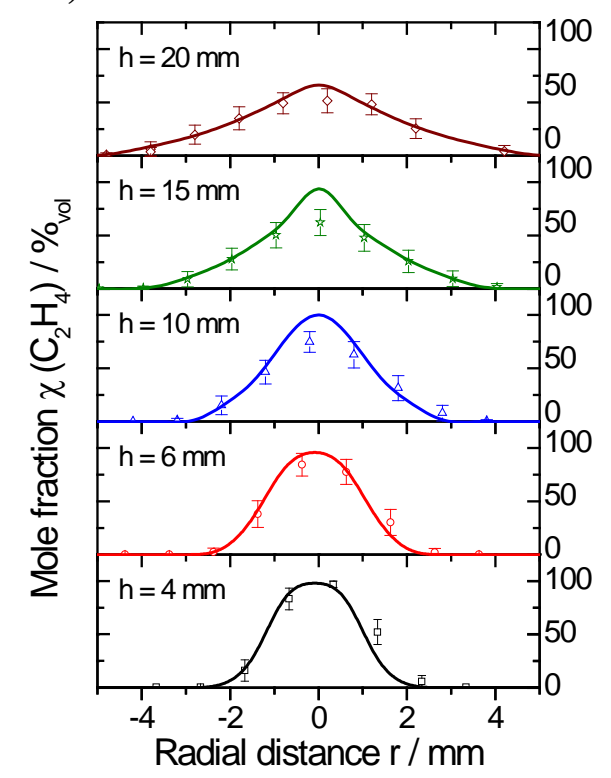

c)

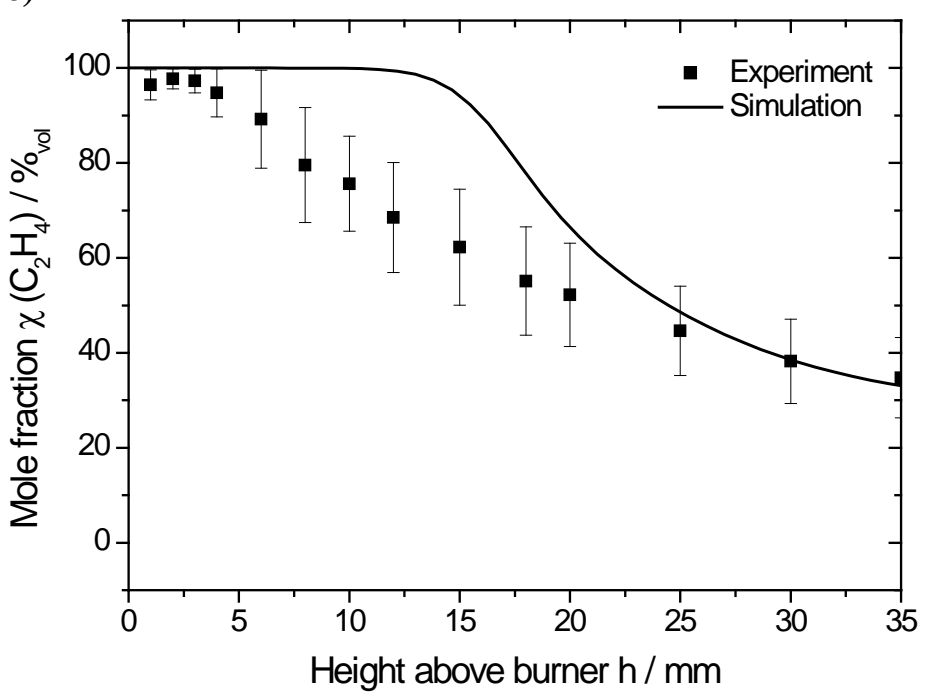


Figure 11: Comparison of measured and simulated $\mathrm{OH}$ distributions with focus on the lift-off region. Color plot is shown for a) the simulated (left) and experimental (right, relative intensity) $\mathrm{OH}$ concentration. Note that the experimental data is slightly shifted from centreline. b) Radial profiles for selected heights.

a)

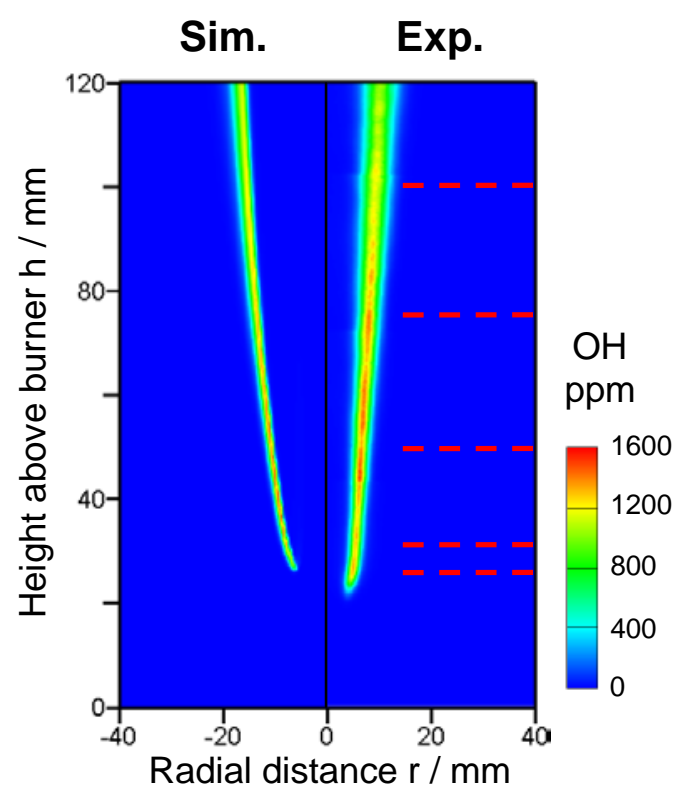

b)

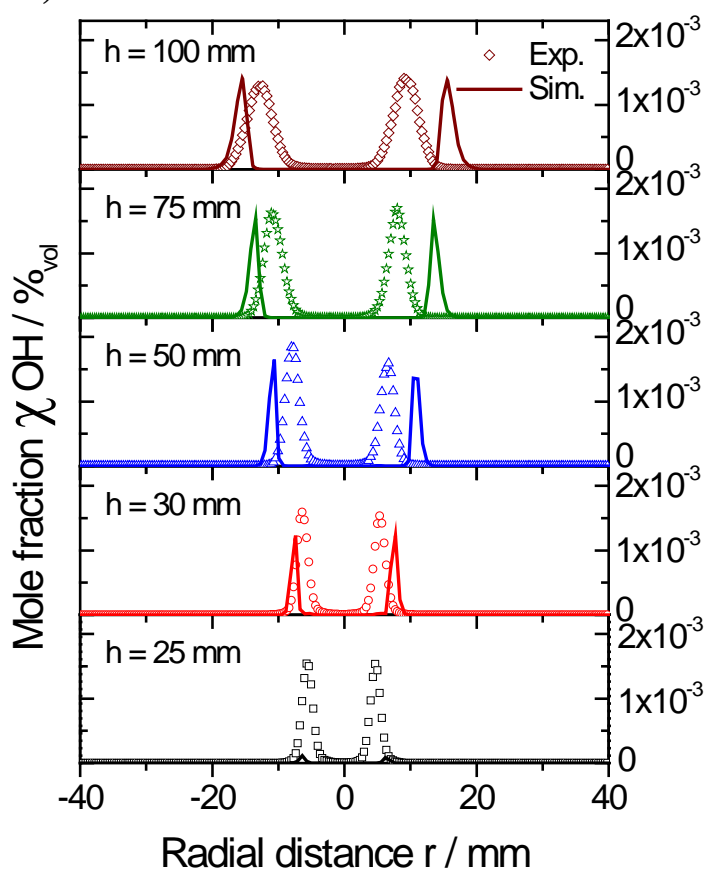


Figure 12: Comparison of measured and simulated PAH distributions with focus on the lift-off region. Color plot is shown for a) the experimental qualitative PAH fluorescence (right) and simulated (left) $\mathrm{PAH}$ concentration; displayed is the first simulated bin $\mathrm{PAH}_{0}$. b) Radial profiles for selected heights; note the different axis scales.

a)

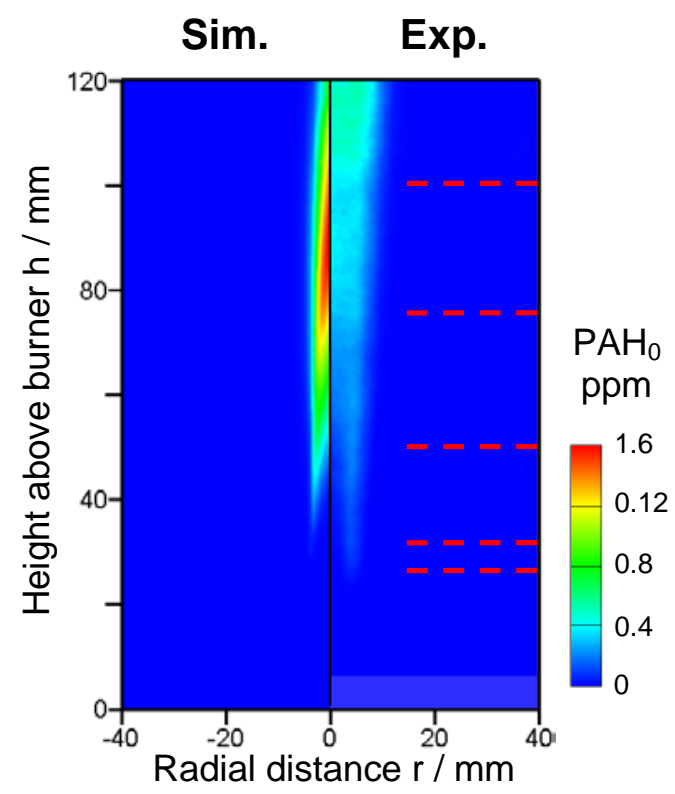

b)

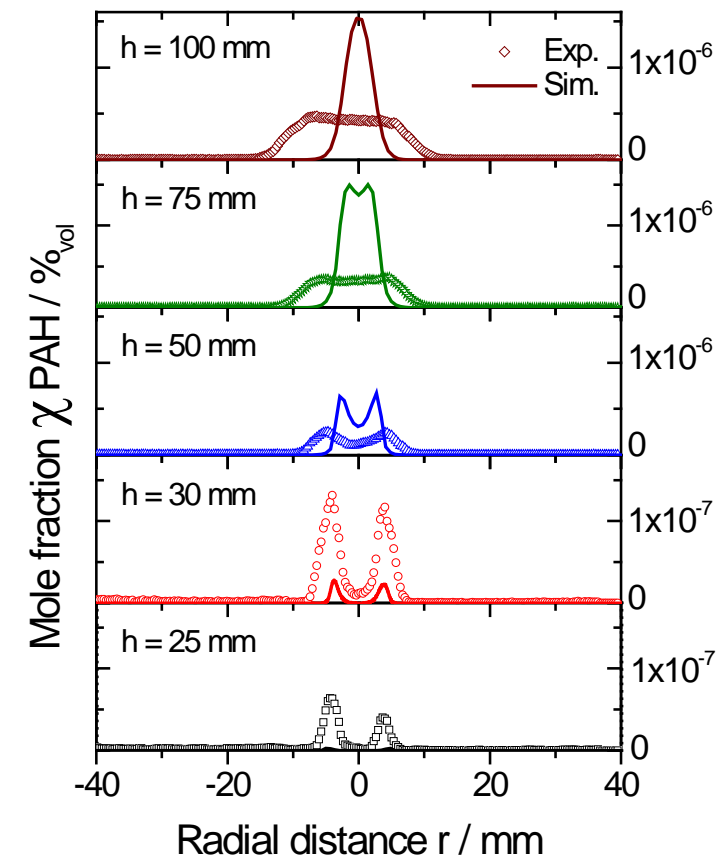


Figure 13: Spatial distributions and overlap of $\mathrm{OH}, \mathrm{PAH}$ and soot on time-average (upper row) and instantaneously (second row). a) OH-PLIF, b) PAH-PLIF, c) binarized image pairs of OH (blue) and PAH (green) - the overlap of both is displayed in yellow, d) LII, e) LII signature (orange) merged into c). The third row displays two more LII single shot events relative to the time-averaged f) $\mathrm{OH}$ and g) PAH distribution. The profile plot $h$ ) on the right visualizes the horizontal time-averaged soot distribution at $\mathrm{h}=25 \mathrm{~mm}$ relative to $\mathrm{OH}$ and $\mathrm{PAH}$ as taken from the upper row.

a)

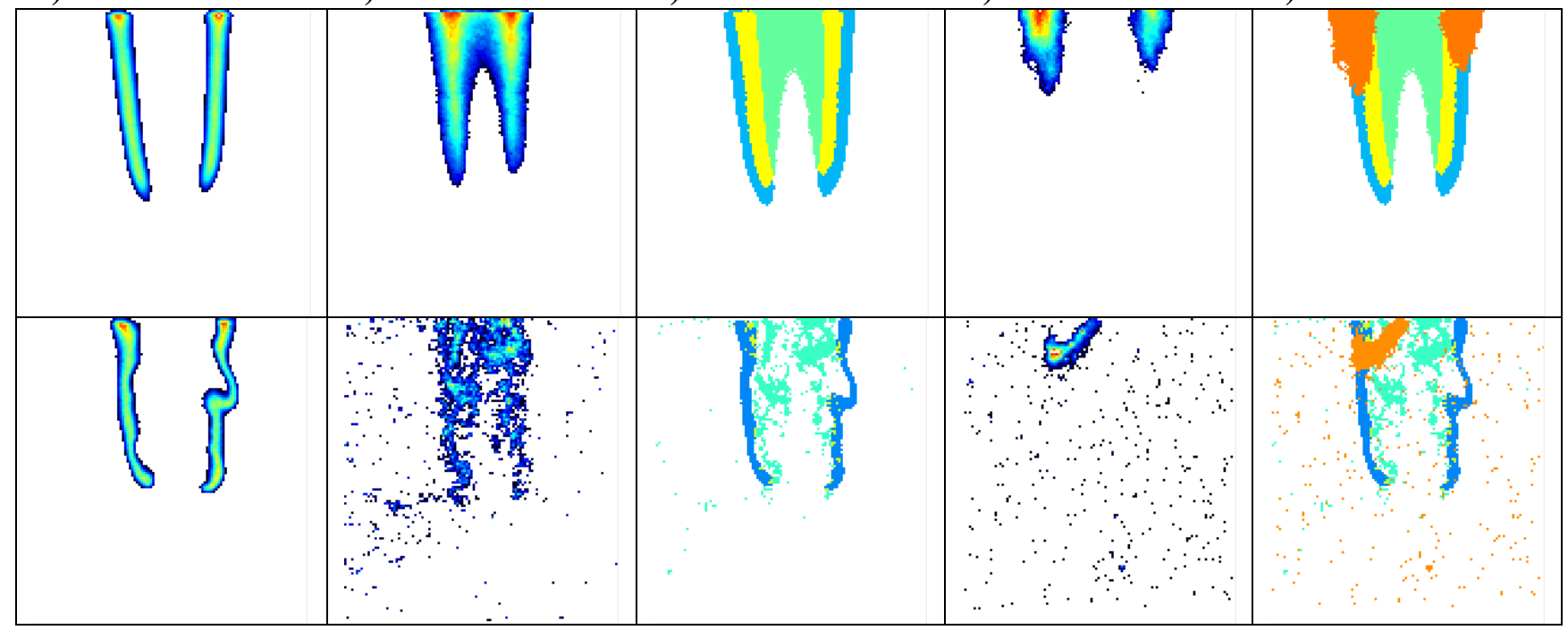

f)

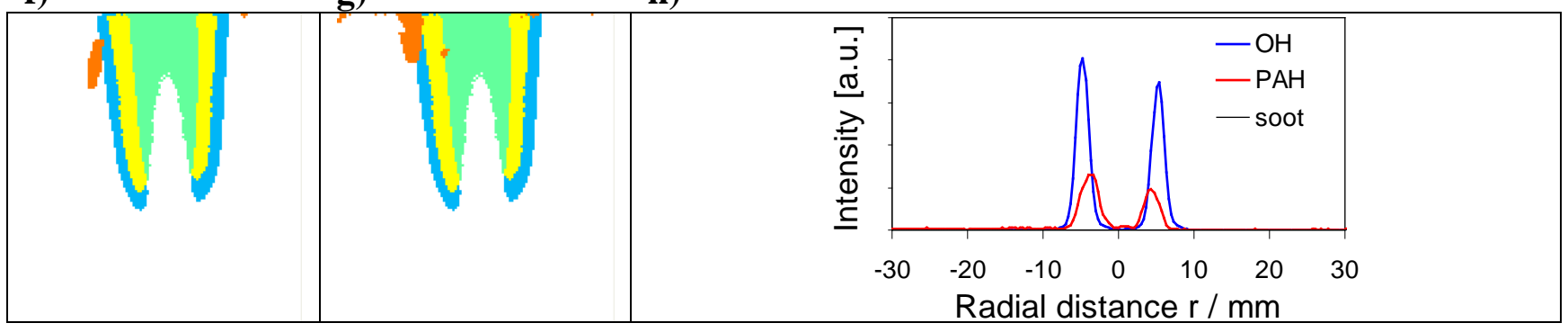


Figure 14: Simulated soot properties. Two dimensional color plots are shown for a) mean particle diameter $\mathrm{d}_{\mathrm{p}}$ and $\mathrm{b}$ ) soot number density $\mathrm{N}_{\mathrm{S}}$.

a)

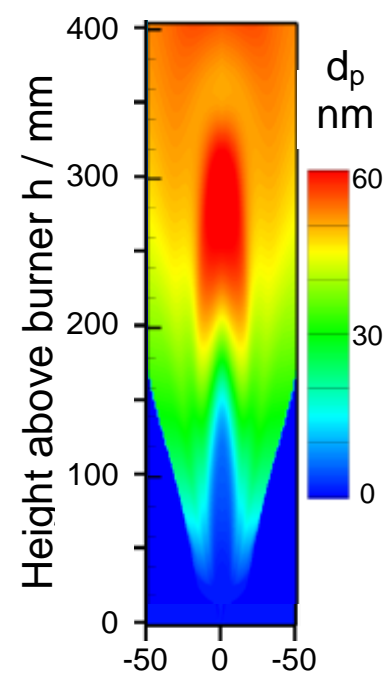

b)

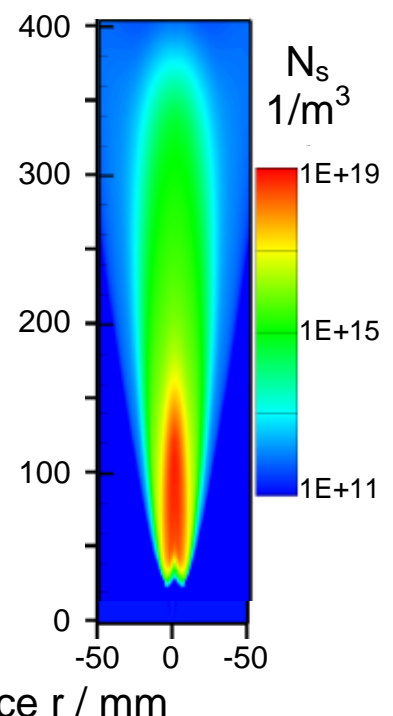

